\title{
Functional magnetic resonance imaging outcomes from a comprehensive magnetic resonance study of children with fetal alcohol spectrum disorders
}

\author{
Susan J. Astley • Elizabeth H. Aylward • \\ Heather Carmichael Olson • Kimberly Kerns • \\ Allison Brooks • Truman E. Coggins • Julian Davies • \\ Susan Dorn • Beth Gendler • Tracy Jirikowic • \\ Paul Kraegel • Kenneth Maravilla • Todd Richards
}

Received: 20 August 2008 / Accepted: 23 January 2009 /Published online: 12 March 2009

(C) Springer Science + Business Media, LLC 2009

\begin{abstract}
A comprehensive neuropsychological/psychiatric, MR imaging, (MRI), MR spectroscopy (MRS), and functional MRI (fMRI) assessment was administered to children with fetal alcohol spectrum disorders (FASD) to determine if global and/or focal abnormalities could be
\end{abstract}

S. J. Astley $(\triangle) \cdot$ A. Brooks $\cdot$ S. Dorn $\cdot$ B. Gendler $\cdot$ P. Kraegel

Department of Epidemiology,

Center on Human Development and Disability,

University of Washington,

Box 357920, Seattle, WA 98195-7920, USA

e-mail: astley@u.washington.edu

E. H. Aylward $\cdot$ K. Maravilla $\cdot$ T. Richards

Department of Radiology, University of Washington,

Seattle, WA 98195, USA

H. C. Olson

Department of Psychiatry and Behavioral Sciences,

University of Washington,

Seattle, WA 98195, USA

K. Kerns

Department of Psychology, University of Victoria,

Victoria, BC V8P 5C2, Canada

T. E. Coggins

Department of Speech and Hearing Sciences,

University of Washington,

Seattle, WA 98195, USA

\section{J. Davies}

Department of Pediatrics, University of Washington,

Seattle, WA 98195, USA

T. Jirikowic

Department of Rehabilitation Medicine, University of Washington,

Seattle, WA 98195, USA identified, and distinguish diagnostic subclassifications across the spectrum. The four study groups included: 1 . FAS/Partial FAS; 2. Static Encephalopathy/Alcohol Exposed (SE/AE); 3. Neurobehavioral Disorder/Alcohol Exposed (ND/AE); and 4. healthy peers with no prenatal alcohol exposure. fMRI outcomes are reported here. The neuropsychological/psychiatric, MRI, and MRS outcomes are reported separately. fMRI was used to assess activation in seven brain regions during performance of $N$-back working memory tasks. Children across the full spectrum of FASD exhibited significant working memory deficits and altered activation patterns in brain regions that are known to be involved in working memory. These results demonstrate the potential research and diagnostic value of this noninvasive MR tool in the field of FASD.

Keywords Fetal alcohol spectrum disorder (FASD) .

Functional magnetic resonance imaging (fMRI) .

Working memory $\cdot$ FASD 4 -Digit Diagnostic Code $\cdot N$-back

\section{Introduction}

Fetal alcohol syndrome (FAS) is a permanent birth defect syndrome caused by maternal alcohol consumption during pregnancy. FAS is defined by growth deficiency, a unique cluster of minor facial anomalies, and central nervous system (CNS) dysfunction and/or structural brain abnormalities [1]. The cognitive/behavioral problems in this condition stem from prenatal brain damage. Not all individuals with prenatal alcohol exposure present with measurable CNS dysfunction or structural brain abnormalities, 
and not all who present with measurable CNS dysfunction or structural brain abnormalities have FAS. Recently, the term Fetal Alcohol Spectrum Disorders (FASD) was coined to depict the spectrum of outcomes observed among individuals with prenatal alcohol exposure. FASD is not a medical diagnosis. Rather, diagnoses like FAS, Partial FAS, Static Encephalopathy/Alcohol Exposed, and Neurobehavioral Disorder/Alcohol Exposed fall under the umbrella of FASD. The degree of brain damage among individuals with prenatal alcohol exposure may vary from microcellular and neurochemical aberrations to gross structural anomalies. Similarly, cognitive/behavioral dysfunction varies along the full continuum from mild developmental delay or learning disabilities to global developmental disability. The specificity of the FAS facial phenotype to prenatal alcohol exposure lends credence to the clinical judgment that the cognitive and behavioral dysfunction observed in individuals with FAS is due, at least in part, to brain damage caused by a teratogen [2-4]. Unfortunately, without the unique facial phenotype of FAS or at least a severe or clinically obvious expression of brain damage, the neurodevelopmental disabilities of an individual affected by prenatal alcohol exposure often go unrecognized and inappropriately served [5].

Many individuals with prenatal alcohol exposure exhibit cognitive difficulties and significant maladaptation that prevent them from leading productive, independent lives $[6,7]$. Across the population, the profile of cognitive dysfunction among individuals with prenatal alcohol exposure is highly variable, though there are some commonalities in functional compromise among subgroups, and conceptual models of overarching deficits have been proposed [8]. However, no single behavioral phenotype specific to alcohol teratogenicity has been described. Without a behavioral phenotype specific to the teratogen alcohol, attributing an alcohol-exposed child's dysfunction to brain damage is often questionable at a clinical level [4]. If indisputable evidence of brain damage (e.g., alterations in neurostructure, neurometabolites and/or neuroactivation) could be found in these individuals, and linked to behavioral deficit, diagnostic efforts could be improved. The "disability" of these alcohol-exposed children would be clearly established, and help facilitate eligibility for needed services. Further, if specific alterations in neurostructure, neurometabolites, and/or neuroactivation could be linked to clinically meaningful, discrete neuropsychological deficits, development of appropriate intervention programs could be accelerated.

The overall goal of this research study was to determine if magnetic resonance imaging, (MRI), magnetic resonance spectroscopy (MRS), and/or functional MRI (fMRI) could serve as non-invasive methods for definitively identifying global and/or focal brain abnormality across the full continuum of FASD, and distinguish diagnostic subclassifications within the spectrum. The results of this comprehensive study are presented in four separate reports: fMRI (presented here), and the neuropsychological/ behavioral [9], MRI (submitted for publication), and MRS [10] outcomes reported separately.

fMRI is a potentially powerful tool that can assess regional brain activation in response to performance on specific cognitive, perceptual, or motor tasks. Many studies, spanning a broad array of disease states and disorders, have used this tool to document activation that is different in intensity and/or spatial extent in subjects with brain damage and/or impairment on the specific tasks being assessed [1113]. Only three FASD fMRI studies have been published to date. Significant differences in brain activation patterns were observed between FASD and Control groups during verbal learning [14], response inhibition [15], and spacial working memory [16] tasks. All of these tasks require higher-order cognitive abilities that are often deficient in individuals with FASD [17-21]. All three studies clearly demonstrated the value of fMRI in this clinical population. The present study extends this line of inquiry to nonspatial working memory, using an fMRI $N$-back paradigm. Working memory is the ability to hold and manipulate information online in the brain $[22,23]$. The constituent processes involved in working memory are encoding, rehearsal, storage, and executive processes on the contents of stored memory [13]. Working memory is subserved by a neurocognitive network comprising regions involved in attention (anterior cingulate), executive function (dorsolateral prefrontal cortex), and short-term mnemonic strategies (parietal cortex and precuneous) [24-26].

\section{Materials and methods}

\section{Subjects and study groups}

The protocol was approved by the University of Washington Human Subjects Review Board. The three FASD groups were selected from among 1,200 patients previously diagnosed by an interdisciplinary team in the WA State FAS Diagnostic \& Prevention Network (FAS DPN) of clinics using the FASD 4-Digit Code [27, 28]. Briefly, the four digits of the FASD 4-Digit Code reflect the magnitude of expression of the four key diagnostic features of FASD, in the following order: (1) growth deficiency, (2) characteristic FAS facial phenotype, (3) CNS structural/functional abnormalities, and (4) prenatal alcohol exposure (Fig. 1). The magnitude of expression of each feature is ranked independently on a four-point Likert scale, with 1 reflecting complete absence of the FASD feature and 4 reflecting a strong "classic" presence of the FASD feature. Each Likert 
Fig. 1 a FASD 4-Digit

Diagnostic Code grid. FASD is defined by growth deficiency, specific FAS facial features, evidence of CNS damage and prenatal alcohol exposure. The 4-Digit Code ranks each of these areas on four-point, casedefined, Likert scales. The 4Digit Code (3444) inserted in the grid is one of 12 codes that meet the diagnostic criteria for FAS. b FASD 4-Digit Code FAS facial phenotype. The rank 4 FAS facial phenotype as defined by the 4-Digit Diagnostic Code requires the presence of all three of the following anomalies: (1) palpebral fissure lengths 2 or more standard deviations below the norm mean; (2) a smooth philtrum (rank 4 or 5 on the Lip-Philtrum Guide), and (3) a thin upper lip (rank 4 or 5 on the Lip-Philtrum Guide). Examples of the rank 4 FAS facial phenotype for Caucasian, Native American, African American, and Asian American children are shown. (C) 2009 University of Washington. Reproduced with permission from Susan Astley, Ph.D.

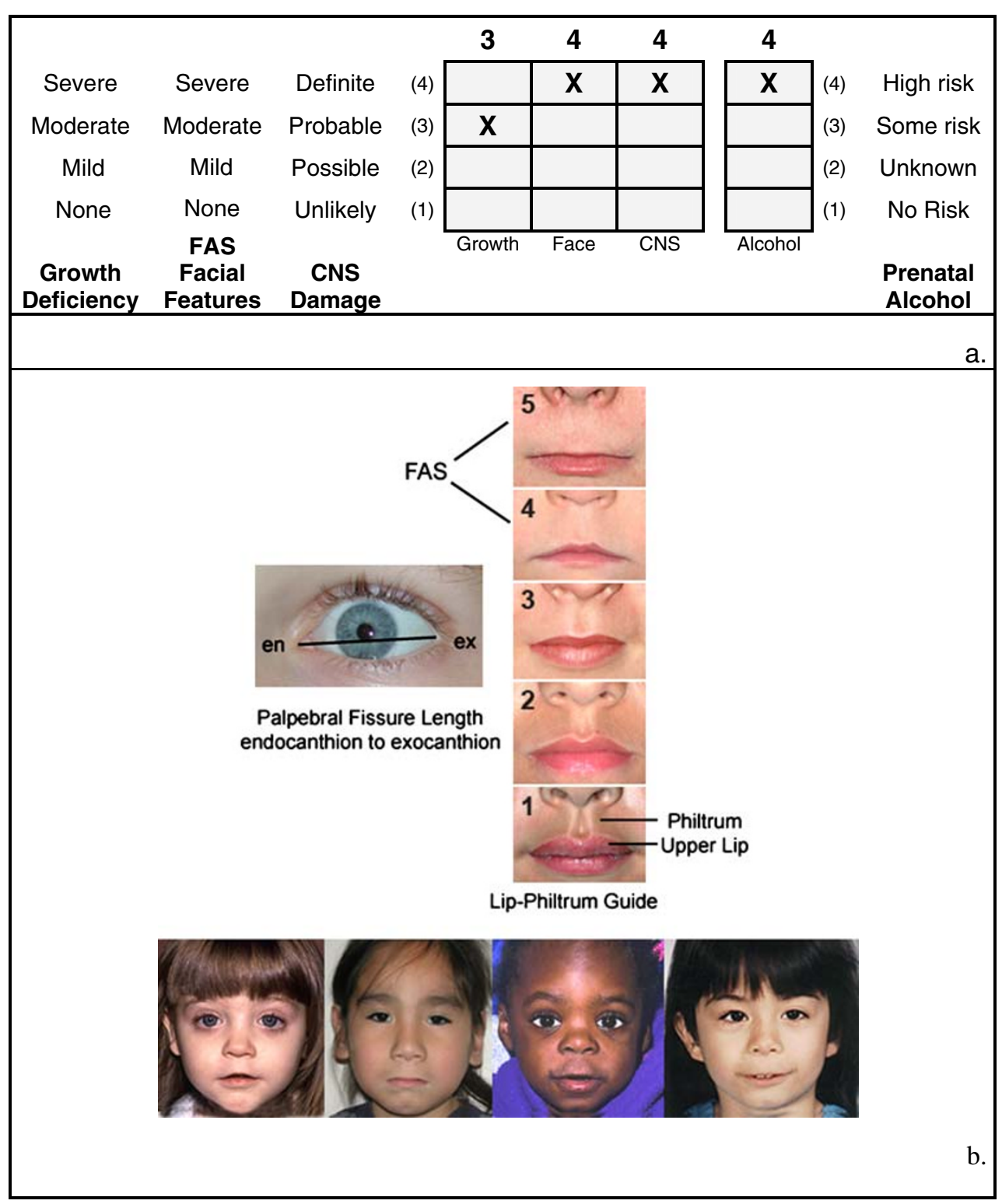

rank is specifically case defined. There are 256 possible 4Digit Diagnostic Codes, ranging from 1,111 to 4,444. Each 4-Digit Diagnostic Code falls into one of 22 unique clinical diagnostic categories (labeled A through V). Seven of the 22 diagnostic categories (4-Digit Categories A-C and E-H) fall under the umbrella of FASD (A. FAS/Alcohol Exposed, B. FAS/Alcohol Exposure Unknown, C. Partial FAS/ Alcohol Exposed, E-F. Static Encephalopathy/Alcohol Exposed, and G-H. Neurobehavioral Disorder/Alcohol Exposed). The three FASD study groups in the current study represent these FASD diagnostic categories. The control population was selected primarily from a large cohort of children enrolled at birth in a University of Washington study of typical development conducted through the Department of Speech and Hearing Sciences.
With the enrollment of each child in the FAS/PFAS group, a child matched on age (within 6 months), gender, and race was randomly identified and invited to enroll from the eligible SE/AE, ND/AE and Control populations. A stratified-randomized block design was used to select children with FAS/PFAS from the eligible clinic population to achieve an equal distribution of gender, the full eligible age range (8-15.9 years), and a racial distribution that matched the clinic population.

The study enrollment procedure produced a sample of 81 children in the overall MR study [9]. A representative subset of 71 children contributed data to the fMRI component of this study (Table 1). Each of the four fMRI study groups had 13-22 subjects successfully balanced on age, gender, and race. Each study group spanned the full 
Table 1 Sociodemographic and FASD 4-Digit Diagnostic Code profile of the four study groups that participated in the fMRI study

\begin{tabular}{|c|c|c|c|c|c|}
\hline \multicolumn{2}{|l|}{ Characteristic } & \multirow{2}{*}{$\begin{array}{l}\begin{array}{l}\text { 1. FAS/PFAS } \\
N=16 \\
7(43.8)\end{array}\end{array}$} & \multirow{2}{*}{$\begin{array}{l}\begin{array}{l}\text { 2. } \mathrm{SE} / \mathrm{AE} \\
N=22 \\
8(36.4)\end{array}\end{array}$} & \multirow{2}{*}{$\begin{array}{l}\begin{array}{l}\text { 3. ND/AE } \\
N=20\end{array} \\
10(50.0)\end{array}$} & \multirow{2}{*}{$\begin{array}{l}\begin{array}{l}\text { 4. Control } \\
N=13\end{array} \\
6(46.2)\end{array}$} \\
\hline Gender: $n(\%)^{\mathrm{a}}$ & Female & & & & \\
\hline Age at enrollment (years): mean $(\mathrm{SD})^{\mathrm{b}}$ & & $13.3(2.0)$ & $12.4(2.0)$ & $12.5(2.2)$ & $12.9(2.6)$ \\
\hline \multirow[t]{3}{*}{ Race: $n(\%)^{\mathrm{c}}$} & Caucasian & $11(68.8)$ & $10(45.5)$ & $12(60.0)$ & $10(60.6)$ \\
\hline & Black & $4(25.0)$ & $3(13.6)$ & $5(25.0)$ & $2(15.4)$ \\
\hline & Other & $1(6.3)$ & $9(40.9)$ & $3(15.0)$ & $1(7.7)$ \\
\hline \multirow[t]{4}{*}{ Growth rank from 4-Digit Code: $n(\%)$} & 1. none & $9(56.3)$ & $13(59.1)$ & $12(60.0)$ & $12(92.3)$ \\
\hline & 2. mild & $1(6.3)$ & $2(9.1)$ & $6(30.0)$ & $1(7.7)$ \\
\hline & 3. moderate & $4(25.0)$ & $3(13.6)$ & $1(5.0)$ & $0(0.0)$ \\
\hline & 4. severe & $2(12.5)$ & $4(18.2)$ & $1(5.0)$ & $0(0.0)$ \\
\hline \multirow[t]{4}{*}{ Face rank from 4-Digit Code: $n(\%)$} & 1. none & $0(0.0)$ & $3(13.6)$ & $6(30.0)$ & $9(69.2)$ \\
\hline & 2. mild & $0(0.0)$ & $19(86.4)$ & $14(70.0)$ & $4(30.8)$ \\
\hline & 3. moderate & $3(18.8)$ & $0(0.0)$ & $0(0.0)$ & $0(0.0)$ \\
\hline & 4. severe $^{\mathrm{d}}$ & $13(81.3)$ & $0(0.0)$ & $0(0.0)$ & $0(0.0)$ \\
\hline \multicolumn{6}{|l|}{ CNS ranks $1-3$ from 4-Digit Code } \\
\hline \multirow[t]{3}{*}{ Level of functional impairment: $n(\%)$} & 1. none & $0(0.0)$ & $0(0.0)$ & $0(0.0)$ & $13(100.0)$ \\
\hline & 2. moderate & $0(0.0)$ & $3(13.6)^{\mathrm{g}}$ & $20(100.0)$ & $0(0.0)$ \\
\hline & 3. severe & $16(100.0)$ & $19(86.4)$ & $0(0.0)$ & $0(0.0)$ \\
\hline CNS rank 4 from 4-Digit Code & $\begin{array}{l}\text { Structural/neurological abnormality } \\
\text { present: } n(\%)\end{array}$ & $9(56.3)$ & $6(27.3)$ & $0(0.0)$ & $0(0.0)$ \\
\hline \multirow[t]{4}{*}{ Alcohol rank from 4-Digit Code: n (\%) } & 1. No exposure & $0(0.0)$ & $0(0.0)$ & $0(0.0)$ & $13(100.0)$ \\
\hline & 2. Unknown exposure ${ }^{\mathrm{e}}$ & $1(6.3)$ & $0(0.0)$ & $0(0.0)$ & $0(0.0)$ \\
\hline & $\begin{array}{l}\text { 3. Confirmed exposure. Level } \\
\text { moderate or unknown }\end{array}$ & $5(31.3)$ & $11(50.0)$ & $11(55.0)$ & $0(0.0)$ \\
\hline & 4. Confirmed exposure: Level high & $10(62.5)$ & $11(50.0)$ & $9(45.0)$ & $0(0.0)$ \\
\hline
\end{tabular}

A comprehensive profile of the entire study sample is presented in Astley et al. [9]

${ }^{\text {a }}$ Percent female: chi-square $=0.8$ ( $\left.d f 3\right), p=0.84$

${ }^{\mathrm{b}}$ Mean age: ANOVA $F(3,67) 3.2, p=0.56$

${ }^{\mathrm{c}}$ Percent Caucasian: chi-square $=4.0(\mathrm{df} 3), p=0.26$

${ }^{\mathrm{d}}$ Definition of rank 4 FAS face: palpebral fissure lengths 2 or more SDs below the mean norm, and lip and philtrum are Rank 4 or 5 on the LipPhiltrum Guide [27]

${ }^{\mathrm{e}}$ The one child with unknown prenatal alcohol exposure had full FAS

${ }^{\mathrm{f}}$ Four of the 16 subjects in group 1 had full FAS using the FASD 4-Digit Code. Nine of the 12 PFAS had rank 4 faces, but received a diagnosis of PFAS because of their absence of growth deficiency (growth rank 1)

${ }^{g}$ All three children with moderate functional impairment had structural evidence of brain abnormality (microcephaly)

age range of 8.0 to 15.9 years at the time of enrollment. The diagnostic features specific to each group were as follows:

1. Children in Group 1 had a 4-Digit diagnosis of FAS or Partial FAS (FAS/PFAS) (e.g., 4-Digit Diagnostic Categories A, B, C: with Growth Ranks 1-4, Face Ranks 3-4, CNS Ranks 3 and/or 4, and Alcohol Ranks 2-4) (Fig. 1). Alcohol Rank 2 (unknown exposure) could only be present if the child had a diagnosis of full FAS because the Rank 4 FAS facial features are so specific to prenatal alcohol exposure [3, 29]. Since the only clinical difference between FAS and PFAS in this study was the presence of growth deficiency in the former, FAS and PFAS were combined. Children in Group 1 had severe cognitive/behavioral dysfunction and the FAS facial phenotype.
2. Children in Group 2 had a 4-Digit diagnosis of Static Encephalopathy/Alcohol Exposed (SE/AE) (e.g., 4Digit Diagnostic Categories E and F: with Growth Ranks 1-4, Face Ranks 1-2, CNS Ranks 3 and/or 4, and Alcohol Ranks 3-4). Children in Group 2 had severe cognitive/behavioral dysfunction, comparable to Group 1, but did not have the FAS facial phenotype.

3. Children in Group 3 had a 4-Digit diagnosis of Neurobehavioral Disorder/Alcohol Exposed (ND/AE) (e.g. 4-Digit Diagnostic Categories $\mathrm{G}$ and $\mathrm{H}$ : with Growth Ranks 1-4, Face Ranks 1-2, CNS Rank 2, and Alcohol Ranks 3-4). Children in Group 3 had prenatal alcohol exposure comparable to Groups 1 and 2, but had only mild to moderate cognitive/behavioral dysfunction, and did not have the FAS facial phenotype. 
4. Children in Group 4 (Healthy Controls/No Alcohol Exposure) were selected based on parental report that the child was healthy, had no academic concerns, and no prenatal alcohol exposure (e.g., 4-Digit Diagnostic Category V: with Growth Ranks 1-2, FAS Face Ranks (no restrictions), CNS Rank 1, Alcohol Rank 1).

Using the FASD terminology introduced by the Stratton et al. [6], the SE/AE group most closely reflects 'severe ARND' and the ND/AE group reflects 'mild ARND'. A comprehensive analysis of the between-group differences of these diagnostic features is presented in the neuropsychological/behavioral report for this study [9].

\section{Study participation}

Participation in the study involved five visits over a 4 to 6 week study period. The neuropsycological and sociodemographic data were collected during visits 1 and 2 . The MR data were collected during visits 3 and 4 . Outcomes of the neuropsycological assessments were shared with the caregivers on visit 5 , and submitted to the child's medical record with caregiver consent.

Sociodemographic and clinical assessment

A comprehensive sociodemographic and health/medication history of each child was obtained by parent interview and record review. Information included birth data, growth, and all prenatal and lifetime exposures and adverse events. For subjects with FASD, most information was obtained at the time of their FASD diagnostic evaluation. All controls had a reported absence of prenatal alcohol exposure. All children had a standardized digital facial photograph taken at the time of enrollment. The facial photographs were analyzed using the FAS Facial Analysis Software [30] to document the magnitude of expression of the FAS facial phenotype [29]. A more detailed methodology and analysis of the sociodemographic and FASD diagnostic outcomes, including prenatal alcohol exposure histories, are presented in the neuropsychological/behavioral report from this study [9].

Neuropsychological and psychiatric assessments

A detailed description of the assessment battery and a comprehensive analysis of the between-group differences in neuropsychological outcome are presented in the neuropsychological/behavioral report for this study [9]. Briefly, a comprehensive, standardized assessment battery was administered to each child/caregiver by a psychologist masked to group assignment. The assessment battery was designed to capture the domains of potential neuropsychological impairment seen as the result of the typically diffuse brain damage arising from alcohol teratogenesis $[8,20,31-$ 34]. The neuropsychological/behavioral outcomes served to profile the study groups and confirm the groups were clinically and statistically distinct from one another; fundamental to the interpretation of the MR outcomes.

\section{MR scanner}

All scans (MRI, MRS, and fMRI) were acquired using a General Electric 1.5 Tesla scanner in the Diagnostic Imaging Sciences Center (DISC) at the University of Washington.

\section{MRI and MRS}

The MRI and MRS [10] components of this study are reported separately. Briefly, MRI was used to measure the size of the following brain regions: total brain, frontal lobe, caudate, putamen, hippocampus, corpus callosum, and cerebellar vermis. MRS was used to measure the concentrations of three neurometabolites: (1) choline, a marker of cell membrane stability and myelination, (2) N-acetyl aspartate, a neuronal or axonal marker, and (3) creatine, a marker of metabolic activity in selected brain regions.

\section{fMRI: $N$-back working memory task}

An existing fMRI paradigm [35] was modified for this clinical population to assess activation in specific brain regions during working memory. In agreement with other fMRI studies of working memory [24-26], testing with normal controls using this paradigm demonstrated consistent activation of the dorsolateral prefrontal cortex (DLPFC). The $N$-back task [36] involved viewing a series of images (e.g., faces), one at a time, and deciding whether the present image matched the image presented $n$ images back, where $n$ is 1 or 2 . The images were four male and four female faces. $N$-back paradigms often use numbers for stimuli. Because research indicates alcohol-affected children often have math deficits and difficulty with numbers, faces were selected as the stimuli. Two tasks were developed, one using a 0-back and 1-back condition, and one using a 0-back and 2-back condition. The 0-back (control) condition required the subject to press the button whenever a man's face was presented. The 1-back (activation) condition required the subject to press the button whenever the face they were currently viewing was the same as the one immediately preceding it. The 2-back (activation) condition required the subject to press the button whenever the face they were currently viewing was the same as the one presented two images back. The subjects were presented with a series of 
80 images (one at a time) for each of the 1-back and 2-back tasks. The 80 images for the 1-back task were presented in the following order: the first 20 images represented the 0 back condition with seven man's faces presented in random order. The next 20 images represented the 1-back condition with six randomly placed images meeting the 1-back criteria. The next 20 images returned to the 0-back condition with seven man's faces presented in random order. The final 20 images presented the 1-back condition with six randomly placed images meeting the 1-back criteria. The 2-back task followed the same pattern alternating the 0-back and 2-back conditions. Of the 80 images, 26 were positive (the subject should press the button because the image met the $N$-back condition) and 54 were negative (the subject should not press the button because the image did not meet the $N$-back condition). The $\mathrm{N}$-back tasks were scored based on the number of truepositive, true-negative, false-positive, and false-negative responses recorded across the 80 images. Subject's reaction times (ms) also were measured.

To collect meaningful activation data during an $\mathrm{N}$-back task, it is essential for subjects to be actively engaged in the task while lying perfectly still in the scanner. To prepare the child for the fMRI session in the scanner, the child was acclimated to the scanner environment in the mock scanner. A single practice session of the $\mathrm{N}$-back task was administered to the child while in the mock scanner, to confirm the child understood the task well enough to perform it in the real scanner. Children performing with $>65 \%$ accuracy on the practice version of the 1-back task were scanned using the 1-back condition. Children performing with $>65 \%$ on the practice version of the 2-back task were scanned using the 2back condition. Children performing at $<65 \%$ accuracy on the $N$-back tasks were unlikely to perform the tasks in the scanner so as to yield meaningful activation data. Once in the scanner, only data from $N$-back tasks where the number of true-positive and true-negative responses were $>65 \%$ correct were used to assess activation.

\section{fMRI acquisition and analysis}

Scans were acquired on a $1.5 \mathrm{~T}$ GE Signa MR scanner, using a 21 slice blood oxygenation level-dependent (BOLD) EPI pulse sequence with the following parameters: gradient echo pulse, $\mathrm{TR}=3,000 \mathrm{~ms}, \mathrm{TE}=50 \mathrm{~ms}$, flip angle $=$ 90 , matrix $=64 \times 64, F O V=24$, slice thickness $=6.0 \mathrm{~mm}$, 0 gap. Two scans were acquired; one during the 1-back task and one during the 2-back task. Each scan lasted 5 min and $18 \mathrm{~s}$. The 1-back task included two repetitions of the following: $18 \mathrm{~s}$ of fixation, followed by $6 \mathrm{~s}$ of instruction, $60 \mathrm{~s}$ of 0 -back (control) condition, $6 \mathrm{~s}$ of instruction, and $60 \mathrm{~s}$ of 1-back (activation) condition. The scan ended with another $18 \mathrm{~s}$ of fixation. The 2-back task followed the same pattern, using the 2-back condition for the activation condition.

Data from the fMRI scans were transferred from the scanner to the UNIX workstation, globally normalized, and archived on CD-ROMs. fMRI scans were analyzed using the software package MEDx 3.2, a multimodal radiological image processing program (Sensor Systems, Sterling, VA), run on a workstation with Linux operating system software. Motion detection was performed using a center-of-intensity plot. Scans with greater than five volumes with motion that exceed $0.3 \mathrm{~mm}$ from the center of intensity in any plane were considered unusable.

For scans with motion not exceeding this threshold, motion correction was performed, using the AIR algorithm [37, 38] (version 3.08, including the alignlinear and alignwarp programs). This algorithm minimizes the variance of the ratio of the intensities of two images. A gradient descent search was performed to arrive at a global minimum. All images were registered to the same reference image normalized to Tailarach space. A linear rigid body (six parameter) model, with trilinear interpolation was used. Pixel-by-pixel linear detrending was applied to correct for gradual drift in pixel intensity during the time course of the series. Paradigms were then applied, assigning individual volumes to either the control (0-back) or activation (1- or 2back) conditions. Based on examination of the hemodynamic lag, $3 \mathrm{~s}$ of data were omitted from the beginning of the series. A statistic summarizing the activation difference between control and activation conditions was computed for each voxel. The statistic was computed as that of a twosample $t$-test, and was subsequently transformed to a $Z$ score via the Fisher transformation [11]. Active voxels were then identified as those with $Z$-scores exceeding a fixed threshold (a $z$-score $>3$ ). Previous experience with normal subjects indicated that threshold values in the range of 2.4 6.0 (corresponding to 1 -tailed $P$-value of $<0.0082$ ) provide informative, reliable binary activation maps.

Group maps were first produced for each of the four study groups, and areas of primary activation (for any group) were identified. Consistent with previous literature, these regions included left and right anterior cingulate, parietal lobe, particularly the anterior parietal region, dorsolateral prefrontal, inferior frontal, middle frontal and precentral regions of the frontal lobe (Fig. 2). Using the ROIs identified on the template brain, two measures of activation were computed for each subject for each of these brain regions: (1) the number of voxels whose $z$ value exceeded the threshold ( $z=3.0$; cluster corrected), and (2) the average $\mathrm{z}$ score within the region. For each subject and each region, number of activated voxels (i.e., those whose $z$ value exceeded the threshold) was divided by the number of voxels in the region, yielding a measure reflecting the percent of activated voxels within the region. Comparison 
Fig. 2 Regions of interest: 1 posterior parietal lobe, 2 anterior parietal lobe, 3 precentral gyrus, 4 middle frontal gyrus, 5 inferior frontal gyrus, and 6 anterior cingulate gyrus
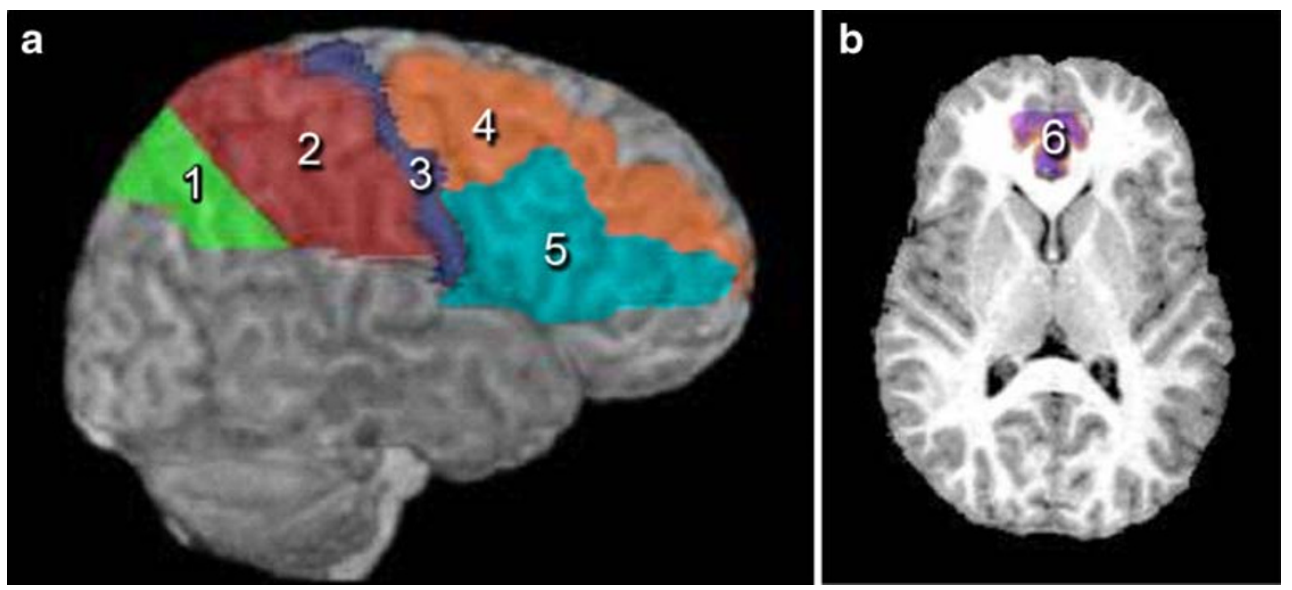

of groups was performed using traditional statistical techniques on these measures.

For clarity, the following nomenclature will be used throughout the remainder of this report. The term 'activation' refers to the difference in activation between the control condition (0-back) and the activation condition (1or 2-back). The term 'task' (as in 1-back task) refers to the 0 -back and 1-back conditions that together make up the 1back task. The term 'condition' (as in 1-back condition) refers to the 1-back condition within the 1-back task.

\section{fMRI hypotheses}

In this report, the neural substrates of working memory in children with FASD were investigated. Given that subjects with FASD have significant deficits in working memory [16] and executive function [17-21] it was hypothesized they would show significant deficits in performance on the $\mathrm{N}$-back tasks. It was also hypothesized that they would show significant alterations in activation in brain regions known to be involved in working memory, since prior FASD fMRI studies have shown activation alterations during memory and response inhibition tasks [14-16]. Trends across the four study groups were hypothesized because the neuropsychological/psychiatric report for this study [9] confirmed the four study groups were clinically distinct and increasingly more affected as one advanced across the four groups from the Controls to the FAS/PFAS.

1. Performance on the 1-back and 2-back conditions of the $N$-back tasks will decline as one advances across the four study groups from Controls to ND/AE to SE/ AE to FAS/PFAS. Measures of performance include number of true-positive, true-negative, false-positive, and false-negative responses, and subjects' reaction times (seconds) for positive responses.

2. Activation (across the selected brain regions; primarily the DLPFC) will increase or decrease as one advances across the four study groups from Controls to ND/AE to SE/AE to FAS/PFAS. Two measures of activation (summarizing the difference in activation between control and activation conditions) were assessed: (1) the mean activation $z$-score across all voxels in a brain region, and (2) the percent of voxels with an activation $z$-score $>3$ in a brain region.

It was not specified, a priori, whether activation levels among the FASD groups would be higher or lower than the Control group, because this is the first FASD fMRI study of visual working memory, and impairment in brain function can manifest as higher or lower activation relative to a healthy Control group.

\section{Statistical analyses}

Chi-square and oneway ANOVA were used to confirm race, gender and mean age were effectively balanced across the four study groups. ANOVA, including multivariate and repeated measures, were used to test hypotheses 1 and 2 . Full factorial designs, which included all main effects and all interactions for within-subjects factors were used. Factors included group (FAS/PFAS, SE/AE, ND/AE, Control), Task (1-back, 2-back), Condition (control, activation), Region (middle frontal gyrus, DLPFC, posterior parietal lobe, anterior parietal lobe, inferior frontal gyrus, precentral gyrus, anterior cingulate gyrus), and hemisphere (right, left). A priori contrasts were used to test for differences among the levels of a factor. For example, a polynomial contrast was included in the ANOVA to determine if mean outcomes changed incrementally as one advanced across the four study groups from Control to FAS/PFAS. Significant linear trends across these four study groups were observed in the magnitude of neuropsychological impairment [9] and reduction in size of brain regions. If significant differences existed among group means, the Duncan post hoc range test was used to identify which groups differed. The Duncan test makes pairwise comparisons using a stepwise procedure. Means are ordered 
from highest to lowest, and extreme differences are tested first. The Duncan test sets a protection level for the error rate for the collection of tests and identifies homogeneous subsets of means that are not different from one another at the $p=0.05$ level. Two-tailed $p$-values of 0.05 were used throughout the analyses.

\section{Results}

Proportion of subjects who were able to participate successfully in $N$-back-fMRI tasks

Seventy-one of the 81 children enrolled in the larger MR study were able to participate successfully in the $N$-back tasks and fMRI evaluation (Table 2). To obtain valid activation data, the subject had to: (1) provide adequate performance/effort during the $N$-back tasks (the child had to be engaged throughout the task, even if they failed to get the correct answers), and (2) lay sufficiently still throughout the scan. Because of the cognitive/behavioral impairment of our FASD study groups, there was concern that many would not be able to successfully participate in the fMRI portion of the study. Only one subject in each study group failed to demonstrate adequate performance/effort during the 1-back task (Table 2). Adequate performance/effort was defined as $>65 \%$ correct true-positive and true-negative responses with active response throughout the task. One to four subjects per group failed to demonstrate adequate performance/effort during the more difficult 2-back task. Subjects in the alcohol-exposed groups were more likely to perform below criteria on the 2-back task than Controls, but the group contrasts were not significantly different. The subjects in the FAS/PFAS were more likely to have difficulty in adapting adequately to the scanner (entering the scanner or lying still within the scanner) in order to produce valid fMRI data, than the remaining groups, but this contrast was also not statistically significant (Table 2). Overall, the subset of 71 children (16/20 FAS/PFAS, 22/24 SE/AE, 20/21 ND/AE and 13/16 Controls) who were able to participate successfully in this fMRI study were highly representative (clinically and sociodemographically) of the full set of 81 children enrolled in the larger MR study.

As described in the neuropsycological/behavioral report from this study [9], two subjects in the FAS/PFAS group had agenesis (ACC) and hypogenesis (HCC) of the corpus callosum. These anomalies were known prior to enrollment into the study. The subject with ACC was able to provide adequate performance on both $N$-back tasks, but valid activation data could not be obtained. The subject with HCC was not able to provide adequate performance on either $\mathrm{N}$-back task, thus activation data were not assessed. As a consequence, data on these two individuals are not included in this report.

$\mathrm{N}$-back performance across the four study groups (hypothesis 1)

$N$-back performance did not vary by age, race, or gender in this study population. 1-back Task. Performance and reaction times for the control condition (0-back) were comparable between the four groups (Table 3). The FAS/ PFAS group had significantly poorer performance and longer reaction times than the Control group on the 1-back condition. Performance on the 1-back condition decreased and reaction times increased linearly as one advanced across the four groups from Control to FAS/PFAS. 2-back Task. Performance and reaction times for the control condition (0-back) were again comparable between the four groups (Table 4). The FAS/PFAS group had significantly

Table 2 Number of subjects able to participate successfully in the $N$-back tasks and the fMRI scan across the four study groups

\begin{tabular}{|c|c|c|c|c|}
\hline fMRI $-N$-back task participation & $\begin{array}{l}\text { 1. FAS/PFAS } \\
N=20 \\
N(\%)\end{array}$ & $\begin{array}{l}\text { 2. } \mathrm{SE} / \mathrm{AE} \\
N=24 \\
N(\%)\end{array}$ & $\begin{array}{l}3 . \mathrm{ND} / \mathrm{AE} \\
N=21 \\
N(\%)\end{array}$ & $\begin{array}{l}\text { 4. Control } \\
N=16 \\
N(\%)\end{array}$ \\
\hline \multicolumn{5}{|l|}{ 1-back task } \\
\hline $\begin{array}{l}\text { Unable to enter or lie still in the scanner } \\
\text { Entered scanner }\end{array}$ & $4(20.0)$ & $1(4.2)$ & $0(0.0)$ & $2(12.5)$ \\
\hline $\begin{array}{l}\text { But did not provide adequate performance/effort } \\
\text { And provided adequate performance/effort }{ }^{\mathrm{a}}\end{array}$ & $\begin{array}{c}1(5.0) \\
15(75.0)\end{array}$ & $\begin{array}{c}1(4.2) \\
22(91.6)\end{array}$ & $\begin{array}{c}1(4.7) \\
20(95.3)\end{array}$ & $\begin{array}{c}1(6.3) \\
13(81.3)\end{array}$ \\
\hline \multicolumn{5}{|l|}{ 2-back task } \\
\hline $\begin{array}{l}\text { Unable to enter or lie still in the scanner } \\
\text { Entered scanner }\end{array}$ & $5(25.0)$ & $2(8.3)$ & $2(9.5)$ & $2(12.5)$ \\
\hline But did not provide adequate performance/effor $\mathrm{t}^{\mathrm{a}}$ & $2(10.0)$ & $4(16.7)$ & $3(14.3)$ & $1(6.3)$ \\
\hline And provided adequate performance/effort ${ }^{\mathrm{a}}$ & $13(65.0)$ & $18(75.0)$ & $16(76.2)$ & $13(81.3)$ \\
\hline
\end{tabular}

${ }^{\text {a }}$ Adequate performance on $N$-back was defined as $\geq 65 \%$ correct true-positive and true-negative responses 
poorer performance and longer reaction times than the Control group on the 2-back condition. Performance on the 2-back condition decreased and reaction times increased linearly as one advanced across the four groups from Control to FAS/PFAS. 1-back Condition versus 2-back Condition. In general, children in the FASD study groups performed more poorly with longer reaction times during the more difficult 2-back condition relative to the 1-back condition (Table 5). The Control group performed comparably across 1-back and 2-back conditions, but had significantly longer reaction times during the more difficult 2-back condition.

Activation by brain region across the four study groups during $N$-back tasks (hypothesis 2)

Pattern of activation across brain regions Activation patterns did not vary by age, race or gender in this study population. The level of brain activation during the $N$-back conditions, relative to the control condition, increased across the brain regions in the following order: precentral gyrus, anterior cingulate gyrus, anterior parietal lobe, inferior frontal gyrus, posterior parietal lobe, DLPFC, and middle frontal gyrus (Figs. 3a, b, Tables 6 and 7). This regional pattern of activation was observed bilaterally for both the 1-back and 2-back tasks across each study group. In general, among the Controls, the mean level of activation was significantly greater bilaterally in the anterior parietal lobe, inferior frontal lobe, posterior parietal lobe, DLPFC, and middle frontal gyrus relative to the region with the lowest level of activation (precentral gyrus) (Table 7). Comparable results were obtained regardless of which activation outcome variable was used (mean percent of voxels with a $z$-score $>3$ in each brain region, or mean $z$ score across all voxels in a brain region) (Table 7). Activation patterns did not vary significantly by age, race, or gender in this study population.

1-back task Activation Across Groups. The level of activation (mean percent of voxels with $z$-scores $>3$ ) during the 1-back condition, relative to the control condition, was comparable across all study groups (Table 6, Fig. 3a). The level of activation (when measured as the mean activity $z$ score across all voxels within each brain region) during the 1-back task was also comparable across all study groups (data not shown). Right versus Left Hemisphere Activation. No significant contrasts were observed between mean activation levels in the right versus left hemispheres of each brain region within each group during the 1-back task. Activation and 1-back Task Performance. The level of activation in each region was not significantly correlated with any measure of performance on the 1-back task. All Pearson Correlation Coefficients had two-tailed $p$-values $>$ 0.05 (data not presented). 2-back task Activation across Groups. Activation levels (mean percent of voxels in each brain region with activity $z$-scores $>3$ ) during the 2 -back condition, relative to the control condition, were significantly lower in the FAS/ PFAS group than the Control group in the right posterior parietal lobe, right DLPFC, and right middle frontal regions (Fig. 3b, Table 7). Activation levels (when measured as mean activity $z$-score across all voxels in each brain region) during the 2-back task were significantly lower in the FAS/ PFAS group than the Control group in the right inferior frontal gyrus, right posterior parietal lobe, right DLPFC, and right middle frontal regions (Table 7). Activation levels increased significantly in these regions as one advanced across the four groups from FAS/PFAS to Control. Right versus Left Hemisphere Activation. When significant contrasts were observed between the FAS/PFAS and Control groups, it always involved structures on the right side of the brain. In general, activation was consistently higher (although not statistically significantly) in the right versus left sides of the posterior parietal lobe, DLPFC, and middle frontal gyrus among the Controls during the 2-back task (Table 7). A similar, but weaker pattern was observed among the ND/AE and SE/AE groups. The pattern reversed (left comparable to or higher than right) among the FAS/ PFAS group. Activation and 2-back Task Performance. Performance on the 2-back task was significantly correlated with activation level in several brain regions. More specifically, the higher the activation (mean percent of voxels with $z$-scores $>3$ ) in the R. and L. DLPFC, and R. and L. middle frontal gyrus, the lower the number of error responses (false-positives and false-negatives combined) on the 2-back task. Statistically significant Pearson correlation coefficients ranged from -0.25 to -0.28 .

1-back task versus 2-back task Among Controls, activation (mean $\%$ of voxels with $z$-scores $>3$ ) was significantly higher (2 to five-fold higher) in the 2-back task (2-back condition relative to control condition) than in the 1-back task (1-back condition relative to the control condition). This was observed in all areas except the anterior cingulate and precentral regions (Table 8, Figs. 3a-c). Among the FAS/PFAS subjects, activation (mean $\%$ of voxels with $z$ scores $>3$ ) was not significantly higher (less than two-fold higher) in 2-back task relative to 1-back task across all brain regions (Table 8 , Figs. $3 \mathrm{a}-\mathrm{c}$ ). As one advanced across the four study groups, the number of brain regions that showed a significant increase in activation in 2-back task relative to 1 -back task increased (Table 8 ). The most marked contrasts in activation between 1-back and 2-back tasks occurred in the middle frontal, DLPFC, and posterior parietal lobe regions (Fig. 3c). Important associations were observed between $N$-back performance and neuroactivation levels. Controls were able to perform equally well on both 


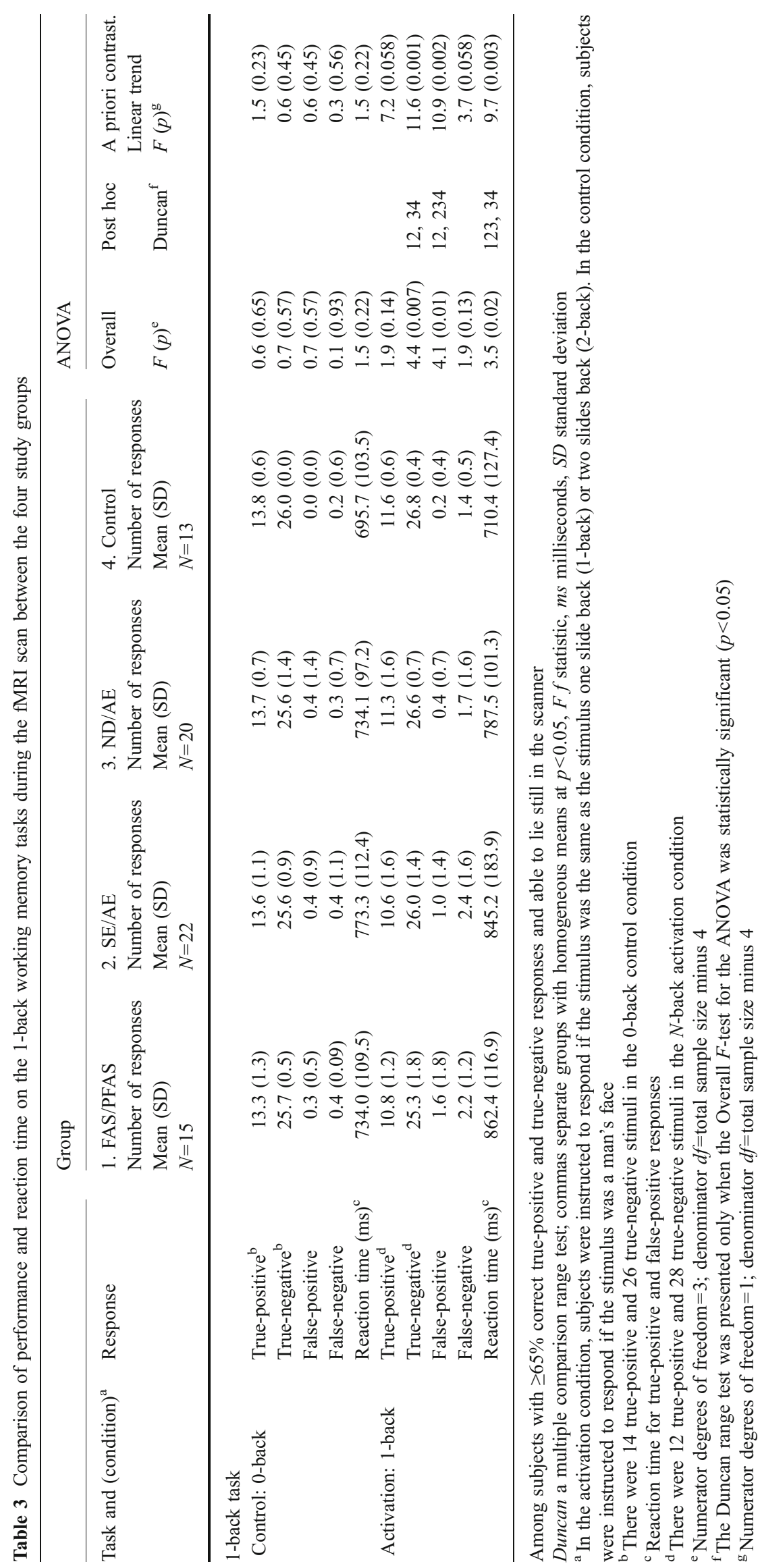




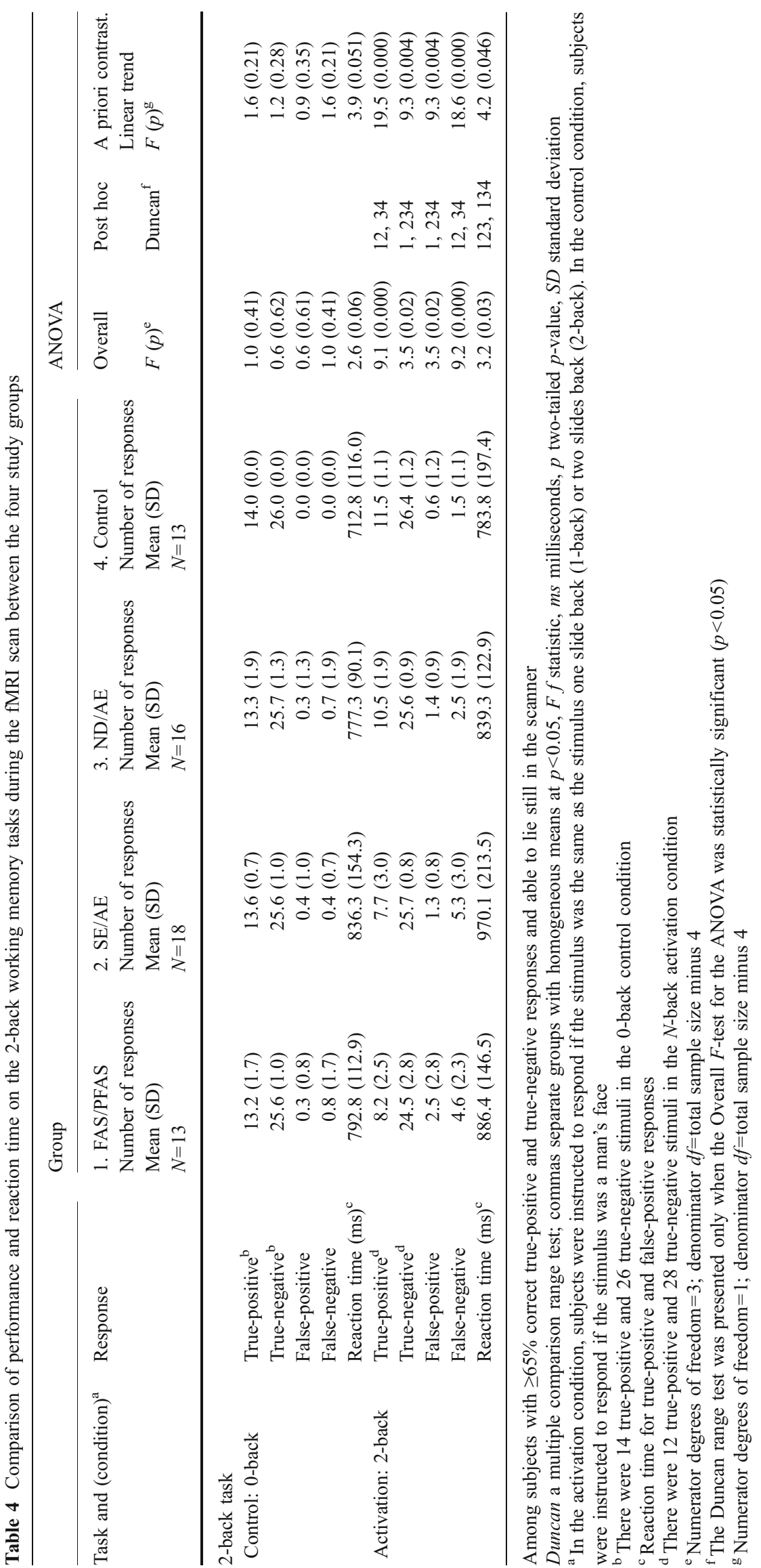


the 1-back and 2-back conditions (e.g., the mean number of correct responses were comparable on 1-back and 2-back conditions) (Table 5, Fig. 4a), but a significantly higher level of activation (five-fold higher) was observed during the more difficult 2-back activation to 'achieve' this outcome (Table 8, Fig. 4b). In contrast, the subjects in the FAS/PFAS group performed significantly worse on the 2back condition relative to the 1-back condition (e.g., the mean number of correct responses was significantly lower on the 2-back than the 1-back condition). And, although the level of activation among the FAS/PFAS was higher during the more difficult 2-back task than the 1-back task, it was considerably lower than the 2-back task activation level observed in the Controls and only two-fold higher than the activation level in the FAS/PFAS during the 1-back task.

\section{Discussion}

Primary fMRI findings

In summary, $74 \%$ of the 81 subjects were able to provide valid fMRI data on both $N$-back tasks, demonstrating that fMRI studies of children with FASD are feasible, albeit challenging. As expected, performance on the 1-back and 2-back conditions decreased significantly as one advanced across the four groups from the Controls to FAS/PFAS. Activation levels decreased significantly on the 2-back task, but not the 1-back task, as one advanced across the four groups from Controls to FAS/PFAS. Decreased BOLD responses during task conditions are thought to reflect decreases in neuronal activation [39]. Controls performed well on both 1-back and 2-back conditions, but showed significantly higher activation during the more difficult 2back task. The FAS/PFAS group performed significantly more poorly on the 2-back condition relative to the 1-back condition, despite a higher (albeit not statistically significant) activation during 2-back task. The increase in activation from the 1-back task to 2-back task in the FAS/ PFAS group, however, was significantly less than the increase observed in the Control group. Of the regions assessed, those with the greatest activity during the $N$-back tasks were the right inferior frontal gyrus, right posterior parietal lobe, right DLPFC, and right middle frontal gyrus. The level of activation during 2-back task in these regions was significantly lower in the FAS/PFAS relative to the Controls, with the SE/AE and ND/AE groups showing levels of activation intermediate to the FAS/PFAS and Controls. When significant contrasts in activation were observed between FAS/PFAS and Controls, the contrasts always involved regions in the right hemisphere. Within each group, reaction times slowed with increasing difficulty

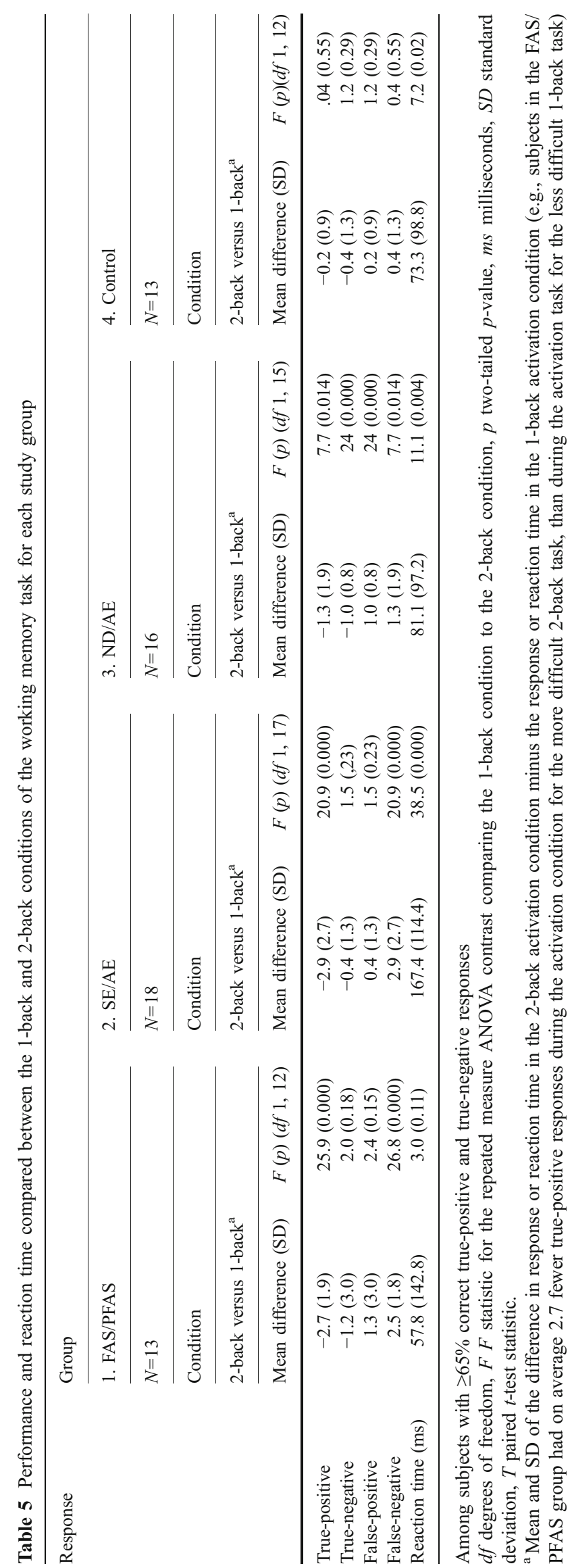


Fig. 3 Activation (mean percent of voxels with $z$-scores $>3$ ) in right brain regions a 1 -back task. b 2-back task. c 1-back task versus 2-back task for three regions with greatest levels of activation: right middle frontal gyrus, DLPFC, and posterior parietal lobe. Key: Brain regions with valid fMRI data: precentral gyrus (orange), anterior cingulate gyrus (blue), anterior parietal lobe (yellow), inferior frontal gyrus (green), posterior parietal lobe (red), dorsolateral prefrontal cortex (purple), middle frontal gyrus (black)

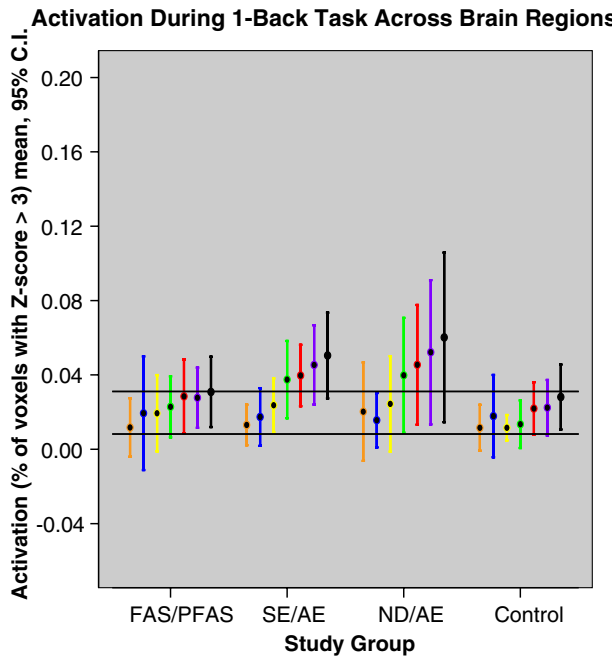

a
Activation During 2-Back Across Brain Regions

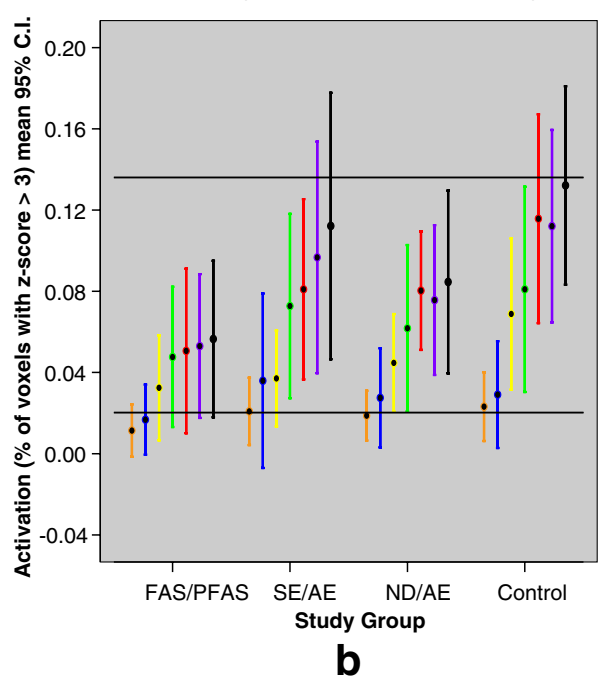

b

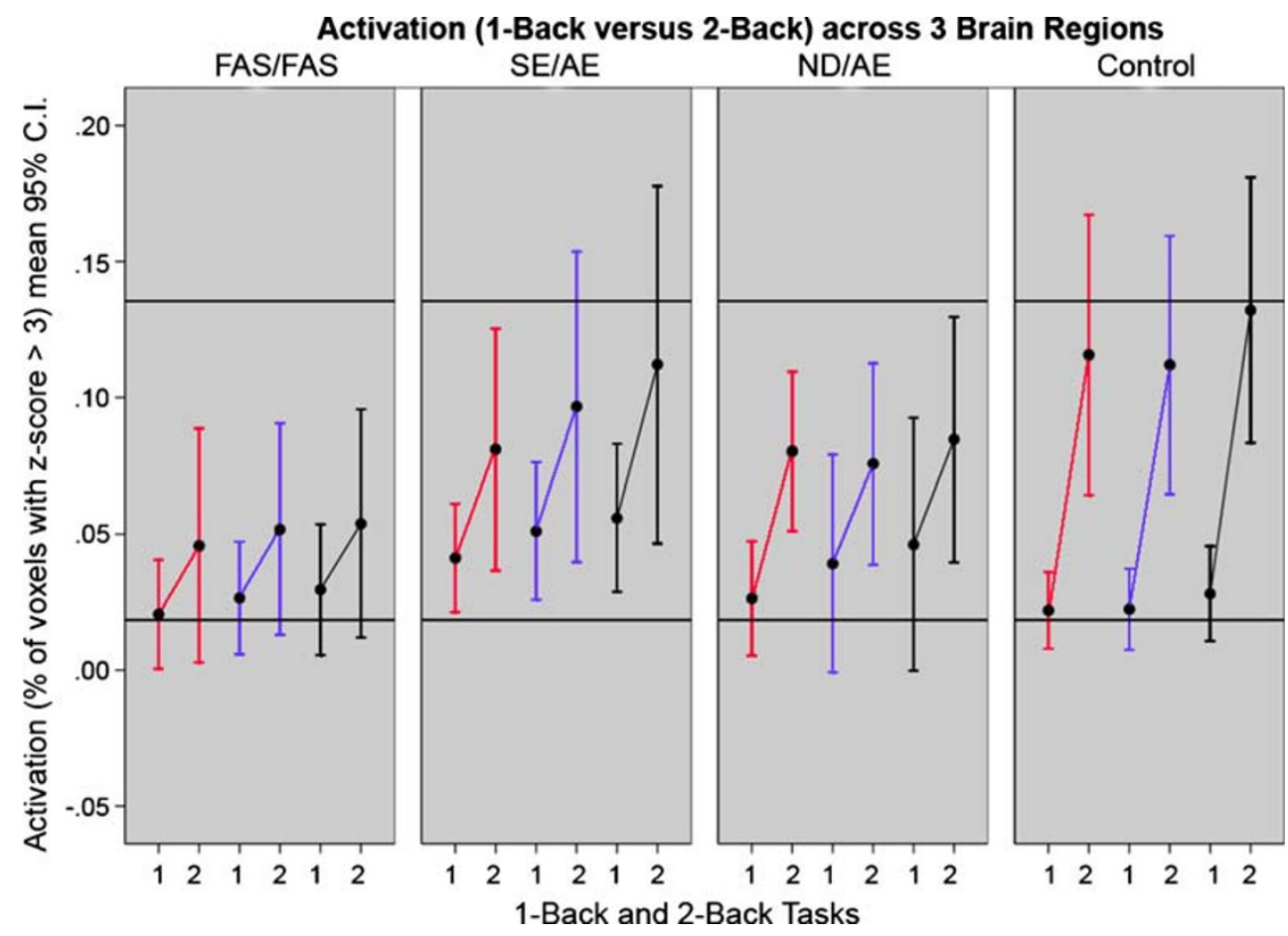

C

of the task. Across the groups, reaction times were slower in the FASD groups than in the Control group.

All groups in the present study showed comparable activation in the anterior cingulate region, which is involved in affective behaviors, nociception, and executive functions [40]. As summarized by Malisza et al. [16], the activity of this region, which is modulated by task demands and response selection, has been shown to increase during working memory tasks in both children and adults [41-43]. These increases, however, may be more closely linked to the attention demands of working memory tasks, than to the memory demands themselves (which have been associated with DLPFC and parietal activations) [43]. In one of the few FASD-fMRI studies conducted to date (and presented more fully below), Malisza et al. [16] 4 also reported consistent activation in the cingulate region across all subjects in their FASD and Control groups. They speculated that the consistent activity may reflect the fact that participants were paying comparable attention to the task; a conclusion strengthened by the fact that their FASD and Control groups performed comparably on a continuous performance task. The consistent anterior cingulate activity observed across the four study groups in the current study may also reflect that participants in all four groups were 
Table 6 Brain activation (mean percent of voxels with activity $z$-scores $>3$ ) in regions of interest during the 1-back working memory condition relative to the control condition, across the four study groups

\begin{tabular}{|c|c|c|c|c|c|c|c|c|}
\hline \multicolumn{2}{|c|}{ Region: in ascending order of activation } & \multicolumn{4}{|l|}{ Group } & \multicolumn{3}{|l|}{ ANOVA } \\
\hline & & $\begin{array}{l}\text { 1. FAS/PFAS } \\
N=15 \\
\text { Mean (SD) }\end{array}$ & $\begin{array}{l}\text { 2. } \mathrm{SE} / \mathrm{AE} \\
N=22 \\
\text { Mean (SD) }\end{array}$ & $\begin{array}{l}\text { 3. ND/AE } \\
N=20 \\
\text { Mean (SD) }\end{array}$ & $\begin{array}{l}\text { 4. Control } \\
N=13 \\
\text { Mean (SD) }\end{array}$ & $\begin{array}{l}\text { Overall } \\
F(p)^{\mathrm{a}}\end{array}$ & $\begin{array}{l}\text { Post hoc } \\
\text { Duncan }^{b}\end{array}$ & $\begin{array}{l}\text { A priori contrast. } \\
\text { Linear trend } \\
F(p)^{\mathrm{c}}\end{array}$ \\
\hline \multirow[t]{2}{*}{ Precentral gyrus } & L. & $0.006(0.009)$ & $0.010(0.013)$ & $0.018(0.056)$ & $0.006(0.009)$ & $0.6(0.64)$ & & $0.1(0.86)$ \\
\hline & R. & $0.012(0.028)$ & $0.013(0.025)$ & $0.020(0.057)$ & $0.012(0.020)$ & $0.3(0.87)$ & & $0.1(0.88)$ \\
\hline \multirow[t]{2}{*}{ Anterior cingulate gyrus } & L. & $0.020(0.049)$ & $0.028(0.059)$ & $0.010(0.016)$ & $0.014(0.023)$ & $0.6(0.60)$ & & $0.4(0.48)$ \\
\hline & $\mathrm{R}$. & $0.019(0.055)$ & $0.017(0.035)$ & $0.016(0.031)$ & $0.012(0.031)$ & $0.1(0.99)$ & & $0.1(0.89)$ \\
\hline \multirow[t]{2}{*}{ Anterior parietal lobe } & L. & $0.022(0.022)$ & $0.025(0.025)$ & $0.029(0.067)$ & $0.029(0.036)$ & $0.1(0.96)$ & & $0.2(0.63)$ \\
\hline & $\mathrm{R}$. & $0.019(0.037)$ & $0.024(0.033)$ & $0.024(0.055)$ & $0.012(0.011)$ & $0.3(0.79)$ & & $0.2(0.62)$ \\
\hline \multirow[t]{2}{*}{ Inferior frontal gyrus } & L. & $0.027(0.032)$ & $0.047(0.046)$ & $0.034(0.043)$ & $0.029(0.029)$ & $0.0(0.98)$ & & $0.1(0.87)$ \\
\hline & $\mathrm{R}$. & $0.023(0.029)$ & $0.038(0.047)$ & $0.039(0.066)$ & $0.013(0.021)$ & $1.1(0.35)$ & & $0.2(0.64)$ \\
\hline \multirow[t]{2}{*}{ Posterior parietal lobe } & $\mathrm{L}$. & $0.032(0.030)$ & $0.036(0.031)$ & $0.044(0.078)$ & $0.039(0.049)$ & $0.2(0.92)$ & & $0.2(0.62)$ \\
\hline & $\mathrm{R}$. & $0.028(0.036)$ & $0.039(0.037)$ & $0.045(0.069)$ & $0.022(0.023)$ & $0.8(0.84)$ & & $0.1(0.80)$ \\
\hline \multirow[t]{2}{*}{ DLPFC } & $\mathrm{L}$. & $0.029(0.029)$ & $0.046(0.034)$ & $0.039(0.049)$ & $0.037(0.037)$ & $0.6(0.63)$ & & $0.1(0.71)$ \\
\hline & $\mathrm{R}$. & $0.028(0.029)$ & $0.045(0.048)$ & $0.052(0.083)$ & $0.022(0.025)$ & $1.1(0.36)$ & & $0.1(0.89)$ \\
\hline \multirow[t]{2}{*}{ Middle frontal gyrus } & $\mathrm{L}$. & $0.031(0.031)$ & $0.045(0.033)$ & $0.043(0.055)$ & $0.043(0.044)$ & $0.4(0.76)$ & & $0.5(0.50)$ \\
\hline & $\mathrm{R}$. & $0.031(0.034)$ & $0.050(0.052)$ & $0.060(0.029)$ & $0.028(0.029)$ & $1.0(0.40)$ & & $0.1(0.98)$ \\
\hline
\end{tabular}

Among subjects with $\geq 65 \%$ correct true-positive and true-negative responses

$D L P F C$ dorsolateral prefrontal cortex, $F f$ statistic, $L$. left, $p$ two-sided $p$-value, $S D$ standard deviation, $R$ right

${ }^{\text {a }}$ Numerator degrees of freedom $=3$; denominator $d f=$ total sample size minus 4

${ }^{\mathrm{b}}$ The Duncan range test was presented only when the overall $F$-test for the ANOVA was statistically significant $(p<0.05)$; commas separate groups with homogeneous means at $p<0.05$

${ }^{\mathrm{c}}$ Numerator degrees of freedom $=1$; denominator $d f=$ total sample size minus 4

paying comparable attention to the task. Perhaps this is an indication that the method used to identify subjects truly engaged in the tasks ( $>65 \%$ correct true-positive and truenegative responses on the $n$-back tasks) was successful. It is also worth noting that event-related fMRI studies [44, 45] have shown activation in the anterior cingulate associated with error commission and detection. More specifically, Kiehl et al. [45] used event-related fMRI techniques to examine the neural responses to appropriate (correct rejects and correct hits) and inappropriate (errors of commission) behavioral responses during a go/no-go task. Analyses of the inappropriate responses revealed extensive activation in the rostral anterior cingulate cortex and in the left lateral frontal cortex. These areas were not activated for correctly classified trials (correct rejects and correct hits). Although significantly more $\mathrm{N}$-back commission errors were observed among the FAS/PFAS group relative to the Controls in the current study, anterior cingulate activation was not higher in the FAS/PFAS group relative to the Controls. Perhaps this reflected an absence of error detection among the FAS/PFAS, which could explain, in part, their poorer performance on $N$-back. When typically developing subjects make an error, their reaction times are typically slower on the subsequent trial $[44,46]$. This phenomenon is considered evidence for central error monitoring. When reaction times during correct responses and commission errors were compared between the FAS/PFAS and Control groups in the current study, the children with FAS/PFAS exhibited significantly less slowing of reaction time after commission errors. For Control subjects, the mean reaction time was significantly slower (mean 207, SD $1.2 \mathrm{~ms}$ ) during commission errors than during correct responses (mean 115, SD $58 \mathrm{~m}$ ) (paired $t=31.9, p=0.03$ ) in the 2-back condition. In contrast, the FAS/PFAS group had comparable reaction times during commission errors and correct responses (mean 212, SD 64 and mean 183, SD 55 respectively) (paired $t=0.3, p=0.80$ ). This observation further supports that the FAS/PFAS group may not have been detecting their errors.

fMRI and working memory in healthy populations

Research on healthy populations suggest regional activation patterns during working memory tasks that closely mirror the findings in our Control group. The DLPFC, posterior parietal cortex, middle frontal gyrus, and Broca's area are essential in successful working memory performance [41, 47-55]. The middle frontal gyrus is known to be important for ongoing storage and maintenance of information [50, $56,57]$, while posterior parietal lobe is seen activated in most working memory tasks with some spatial processing component, and DLPFC is highly activated the greater the 
Table 7 Brain activation in regions of interest during the 2-back working memory condition relative to the control condition, across the four study groups

\begin{tabular}{|c|c|c|c|c|c|c|c|c|}
\hline \multirow[t]{2}{*}{ Region } & & \multicolumn{4}{|l|}{ Group } & \multicolumn{3}{|l|}{ ANOVA } \\
\hline & & $\begin{array}{l}\text { 1. FAS/PFAS } \\
N=13 \\
\text { Mean (SD) }\end{array}$ & $\begin{array}{l}2 . \mathrm{SE} / \mathrm{AE} \\
N=18 \\
\text { Mean (SD) }\end{array}$ & $\begin{array}{l}\text { 3.ND/AE } \\
N=16 \\
\text { Mean (SD) }\end{array}$ & $\begin{array}{l}\text { 4.Control } \\
N=13 \\
\text { Mean (SD) }\end{array}$ & $\begin{array}{l}\text { Overall } \\
F(p)^{\mathrm{a}}\end{array}$ & $\begin{array}{l}\text { Post hoc } \\
\text { Duncan }^{b}\end{array}$ & $\begin{array}{l}\text { A priori contrast. } \\
\text { Linear trend } \\
F(p)^{\mathrm{c}}\end{array}$ \\
\hline \multicolumn{9}{|c|}{ Mean percent of voxels with activity $z$-scores $>3$} \\
\hline Precentral gyrus & $\begin{array}{l}\mathrm{L} . \\
\mathrm{R} .\end{array}$ & $\begin{array}{l}0.021(0.04) \\
0.011(0.02)\end{array}$ & $\begin{array}{l}0.012(0.04) \\
0.021(0.03)\end{array}$ & $\begin{array}{l}0.016(0.02) \\
0.019(0.02)\end{array}$ & $\begin{array}{l}0.008(0.01) \\
0.023(0.03)\end{array}$ & $\begin{array}{l}0.5(0.69) \\
0.5(0.71)\end{array}$ & & $\begin{array}{l}1.1(0.31) \\
1.0(0.32)\end{array}$ \\
\hline Anterior cingulate gyrus & $\begin{array}{l}\mathrm{L} . \\
\mathrm{R} .\end{array}$ & $\begin{array}{l}0.012(0.19) \\
0.017(0.03)\end{array}$ & $\begin{array}{l}0.031(0.09) \\
0.036(0.09)\end{array}$ & $\begin{array}{l}0.028(0.03) \\
0.028(0.05)\end{array}$ & $\begin{array}{l}0.047(0.06) \\
0.029(0.04)\end{array}$ & $\begin{array}{l}0.7(0.54) \\
0.3(0.84)\end{array}$ & & $\begin{array}{l}1.9(0.18) \\
0.2(0.69)\end{array}$ \\
\hline Anterior parietal lobe & $\begin{array}{l}\mathrm{L} . \\
\mathrm{R} .\end{array}$ & $\begin{array}{l}0.043(0.06) \\
0.032(0.04)\end{array}$ & $\begin{array}{l}0.039(0.04) \\
0.037(0.05)\end{array}$ & $\begin{array}{l}0.046(0.04) \\
0.045(0.05)\end{array}$ & $\begin{array}{l}0.080(0.07) \\
0.069(0.06)\end{array}$ & $\begin{array}{l}1.6(0.19) \\
1.5(0.24)\end{array}$ & & $\begin{array}{l}3.1(0.08) \\
3.7(0.06)\end{array}$ \\
\hline Inferior frontal gyrus & $\begin{array}{l}\mathrm{L} . \\
\mathrm{R} .\end{array}$ & $\begin{array}{l}0.056(0.08) \\
0.048(0.06)\end{array}$ & $\begin{array}{l}0.087(0.09) \\
0.073(0.09)\end{array}$ & $\begin{array}{l}0.068(0.06) \\
0.062(0.08)\end{array}$ & $\begin{array}{l}0.076(0.06) \\
0.081(0.08)\end{array}$ & $\begin{array}{l}0.5(0.72) \\
0.4(0.72)\end{array}$ & & $\begin{array}{l}0.2(0.66) \\
0.9(0.37)\end{array}$ \\
\hline Posterior parietal lobe & $\begin{array}{l}\mathrm{L} . \\
\mathrm{R} .\end{array}$ & $\begin{array}{l}0.051(0.07) \\
0.051(0.07)\end{array}$ & $\begin{array}{l}0.059(0.06) \\
0.081(0.09)\end{array}$ & $\begin{array}{l}0.065(0.05) \\
0.080(0.06)\end{array}$ & $\begin{array}{l}0.096(0.07) \\
0.116(0.09)\end{array}$ & $\begin{array}{l}1.4(0.26) \\
3.1(0.05)\end{array}$ & 123,234 & $\begin{array}{l}3.5(0.07) \\
4.4(0.04)\end{array}$ \\
\hline DLPFC & $\begin{array}{l}\mathrm{L} . \\
\mathrm{R} .\end{array}$ & $\begin{array}{l}0.061(0.08) \\
0.053(0.06)\end{array}$ & $\begin{array}{l}0.088(0.08) \\
0.097(0.12)\end{array}$ & $\begin{array}{l}0.083(0.07) \\
0.076(0.07)\end{array}$ & $\begin{array}{l}0.097(0.06) \\
0.112(0.08)\end{array}$ & $\begin{array}{l}0.6(0.60) \\
3.2(0.04)\end{array}$ & 123,234 & $\begin{array}{l}1.4(0.24) \\
2.2(0.14)\end{array}$ \\
\hline Middle frontal gyrus & $\begin{array}{l}\mathrm{L} . \\
\mathrm{R} .\end{array}$ & $\begin{array}{l}0.064(0.08) \\
0.056(0.06)\end{array}$ & $\begin{array}{l}0.089(0.08) \\
0.112(0.13)\end{array}$ & $\begin{array}{l}0.092(0.08) \\
0.085(0.08)\end{array}$ & $\begin{array}{l}0.112(0.07) \\
0.132(0.08)\end{array}$ & $\begin{array}{l}0.9(0.46) \\
3.8(0.01)\end{array}$ & 123,234 & $\begin{array}{l}2.4(0.12) \\
2.9(0.10)\end{array}$ \\
\hline Mean activity $z$-score acro & all & rels & & & & & & \\
\hline Precentral gyrus & $\begin{array}{l}\mathrm{L} . \\
\mathrm{R} .\end{array}$ & $\begin{array}{l}-0.36(0.73) \\
-0.37(0.74)\end{array}$ & $\begin{array}{l}-0.70(0.81) \\
-0.57(0.89)\end{array}$ & $\begin{array}{l}-0.51(0.83) \\
-0.28(0.84)\end{array}$ & $\begin{array}{l}-0.78(0.51) \\
-0.23(0.37)\end{array}$ & $\begin{array}{l}0.9(0.48) \\
0.6(0.59)\end{array}$ & & $\begin{array}{l}1.3(0.26) \\
0.6(0.44)\end{array}$ \\
\hline Anterior cingulate gyrus & $\begin{array}{l}\mathrm{L} . \\
\mathrm{R} .\end{array}$ & $\begin{array}{l}-0.42(0.84) \\
-0.39(0.73)\end{array}$ & $\begin{array}{l}-0.13(1.07) \\
-0.25(1.14)\end{array}$ & $\begin{array}{l}-0.34(0.71) \\
-0.45(0.81)\end{array}$ & $\begin{array}{l}-0.08(0.80) \\
-0.36(0.72)\end{array}$ & $\begin{array}{l}0.5(0.69) \\
0.2(0.92)\end{array}$ & & $\begin{array}{l}0.6(0.45) \\
0.0(0.92)\end{array}$ \\
\hline Anterior parietal lobe & $\begin{array}{l}\mathrm{L} . \\
\mathrm{R} .\end{array}$ & $\begin{array}{r}0.04(0.59) \\
-0.12(0.66)\end{array}$ & $\begin{array}{l}-0.27(0.70) \\
-0.43(0.68)\end{array}$ & $\begin{array}{l}-0.09(0.66) \\
-0.07(0.68)\end{array}$ & $\begin{array}{l}0.20(0.60) \\
0.17(0.62)\end{array}$ & $\begin{array}{l}1.4(0.25) \\
2.1(0.11)\end{array}$ & & $\begin{array}{l}0.7(0.41) \\
2.2(0.14)\end{array}$ \\
\hline Inferior frontal gyrus & $\begin{array}{l}\mathrm{L} . \\
\mathrm{R} .\end{array}$ & $\begin{array}{l}-0.03(0.49) \\
-0.01(0.65)\end{array}$ & $\begin{array}{l}0.36(0.90) \\
0.25(1.04)\end{array}$ & $\begin{array}{l}0.09(0.64) \\
0.25(0.66)\end{array}$ & $\begin{array}{l}0.27(0.71) \\
0.50(0.54)\end{array}$ & $\begin{array}{l}0.9(0.46) \\
1.5(0.23)\end{array}$ & & $\begin{array}{l}0.5(0.47) \\
2.6(0.12)\end{array}$ \\
\hline Posterior parietal lobe & $\begin{array}{l}\mathrm{L} . \\
\mathrm{R} .\end{array}$ & $\begin{array}{l}0.07(0.74) \\
0.02(0.91)\end{array}$ & $\begin{array}{l}0.02(0.74) \\
0.05(0.86)\end{array}$ & $\begin{array}{l}0.19(0.51) \\
0.35(0.54)\end{array}$ & $\begin{array}{l}0.41(0.56) \\
0.65(0.67)\end{array}$ & $\begin{array}{l}1.1(0.38) \\
3.0(0.04)\end{array}$ & 123,34 & $\begin{array}{l}2.3(0.13) \\
5.6(0.02)\end{array}$ \\
\hline DLPFC & $\begin{array}{l}\mathrm{L} . \\
\mathrm{R} .\end{array}$ & $\begin{array}{l}0.05(0.60) \\
0.03(0.70)\end{array}$ & $\begin{array}{l}0.40(0.80) \\
0.41(1.08)\end{array}$ & $\begin{array}{l}0.33(0.59) \\
0.42(0.67)\end{array}$ & $\begin{array}{l}0.46(0.59) \\
0.74(0.43)\end{array}$ & $\begin{array}{l}1.0(0.41) \\
3.3(0.03)\end{array}$ & 123,234 & $\begin{array}{l}2.1(0.16) \\
4.9(0.03)\end{array}$ \\
\hline Middle frontal gyrus & $\begin{array}{l}\mathrm{L} . \\
\mathrm{R} .\end{array}$ & $\begin{array}{l}0.11(0.75) \\
0.06(0.79)\end{array}$ & $\begin{array}{l}0.43(0.81) \\
0.51(1.15)\end{array}$ & $\begin{array}{l}0.48(0.63) \\
0.52(0.77)\end{array}$ & $\begin{array}{l}0.59(0.59) \\
0.90(0.44)\end{array}$ & $\begin{array}{l}1.1(0.34) \\
3.9(0.01)\end{array}$ & 123,234 & $\begin{array}{l}3.0(0.09) \\
5.8(0.02)\end{array}$ \\
\hline
\end{tabular}

Among subjects with $\geq 65 \%$ correct true-positive and true-negative responses

$D L P F C$ dorsolateral prefrontal cortex, $F f$ statistic, $L$. left, $p$ two-tailed $p$-value, $S D$ standard deviation, $R$ right

${ }^{a}$ Numerator degrees of freedom $=3$; denominator $d f=$ total sample size minus 4

${ }^{\mathrm{b}}$ The Duncan range test was presented only when the overall $F$-test for the ANOVA was statistically significant $(p<0.05)$; commas separate groups with homogeneous means at $p<0.05$

${ }^{\mathrm{c}}$ Numerator degrees of freedom $=1$; denominator $d f=$ total sample size minus 4

demands of the task [41, 47, 50, 52, 56, 58, 59] Studies have also observed contrasts in right versus left hemisphere activation that appear to be influenced by age and type of task. Positron emission tomography (PET) involving working memory tasks have shown predominantly right hemisphere activation in the frontal cortex [51, 60], posterior parietal cortex, and anterior cingulate [43] of healthy children and young adults, but bilateral activation in older adults [60]. While spatial working memory tasks activate bilaterally, there are key regions (DLPFC and posterior parietal cortex) that have shown activation predominantly in the right-hemisphere [55]. Smith [23] showed object memory activates right DLPFC.

fMRI and working memory in fragile X syndrome

In an fMRI study of visuospatial working memory among children with fragile $\mathrm{X}$ syndrome, Kwon et al. [13] observed similar outcomes to the present FASD study. Relative to their comparison group, subjects with fragile $\mathrm{X}$ syndrome performed significantly worse on the 2-back task, but not on the 1-back task. In a region-of-interest analysis 


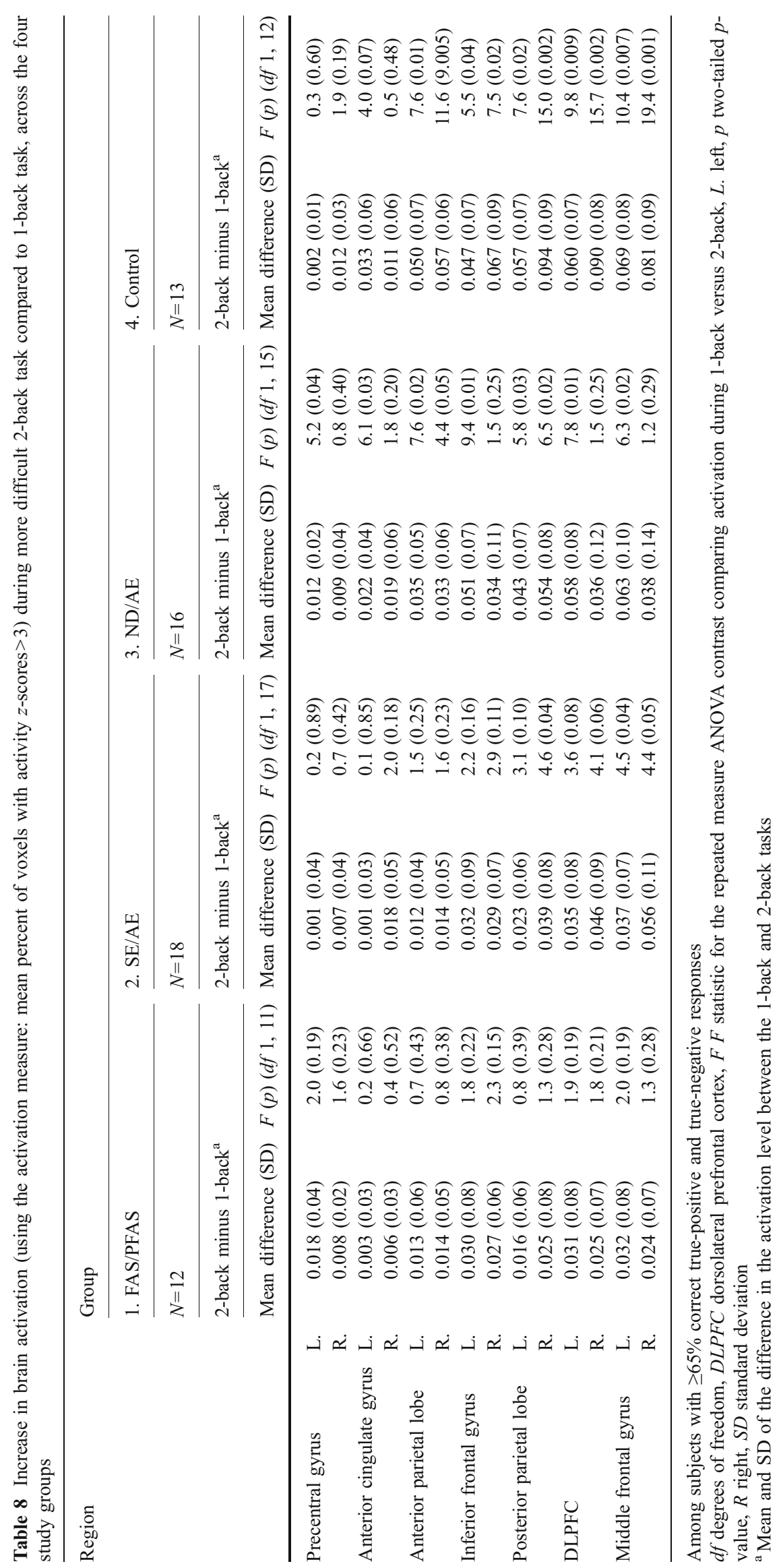


Fig. 4 a Mean number of correct (true-positive and truenegative) responses during 1 back versus 2-back conditions across the four groups. b Increase in activation (mean percent of voxels with $z$-score $>3$ ) during 1-back task versus 2back task across the four groups in the right dorsolateral prefrontal cortex $(D L P F C)$
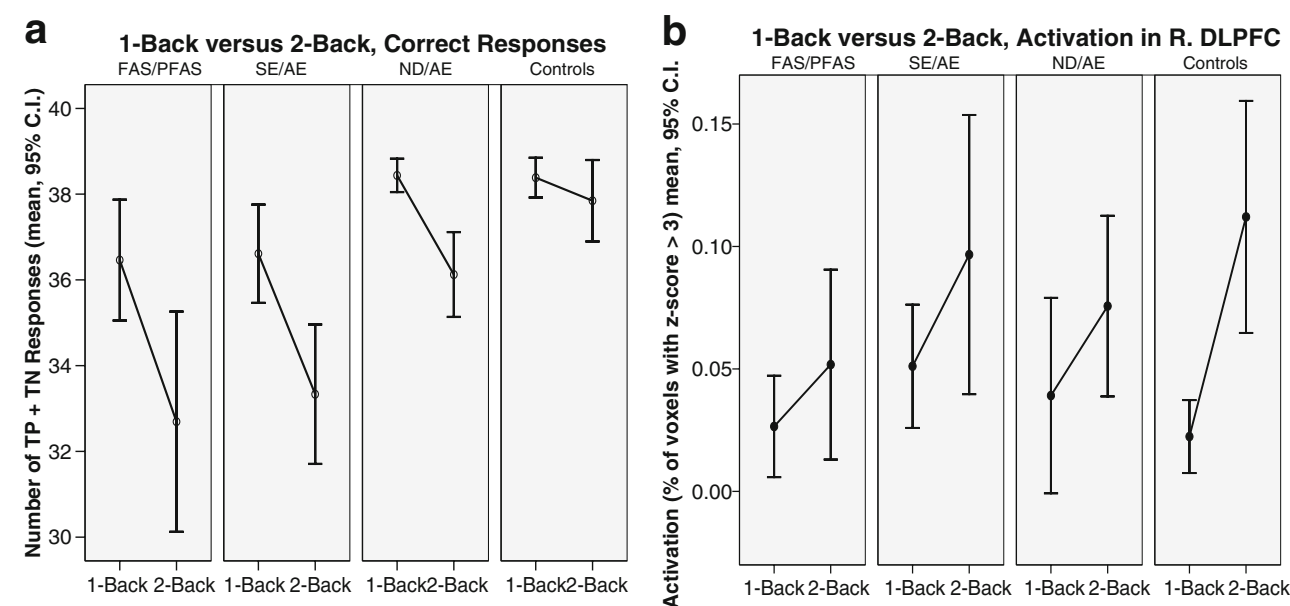

focused on the inferior frontal gyrus, middle frontal gyrus, superior parietal lobule, and supramarginal gyrus, comparison subjects showed significantly increased brain activation between the 1-back and 2-back tasks, but subjects with fragile $\mathrm{X}$ syndrome showed no change in activation between the two tasks. The investigators concluded that subjects with fragile X syndrome were unable to modulate activation in the prefrontal and parietal cortex in response to an increasing working memory load. They speculated these findings may be explained by a ceiling effect. The subjects with fragile $\mathrm{X}$ syndrome may have recruited all of their neuronal resources needed for working memory in the 1-back task. In the 2-back task, the fragile $\mathrm{X}$ syndrome group experienced significant deterioration in performance with a lack of coherent recruitment in areas subserving working memory.

It is interesting to note in the current study that during the 1-back task, the FAS/PFAS group exhibited activation levels that were comparable (if not slightly higher) than the Controls, but demonstrated significantly poorer 1-back performance. During the more difficult 2-back task, both activation and performance were significantly lower in the FAS/PFAS group than the Control group. One might speculate that the 1-back outcome reflected 'neural inefficiency' [12, 61], while the 2-back outcome reflected a 'ceiling effect' [13]. What is 'neuronal inefficiency'? Casey [12] postulated in an fMRI study of nonspatial working memory in healthy children, that incomplete myelination may result in poorer conduction efficiency and thus greater energy expenditure. And, in an fMRI study of working memory in girls with and without ADHD, significantly higher activation in the DLPFC was observed among the girls with ADHD, despite comparable working memory performance [61]. The investigators interpreted these findings as evidence of neural inefficiency. In the present FASD study, evidence of significant white matter/myelin deficiencies, and poorer performance despite comparable activation levels were observed in the FAS/PFAS group relative to the
Controls. One could postulate that if the requisite neuronal resources for the 1-back task were deficient and/or inefficient in our FAS/PFAS group, comparable activation could have produced inferior performance. When the more difficult 2-back task is encountered, a ceiling effect [13] may have occurred. The Control group demonstrated that a significantly higher level of activation was required to achieve accurate performance on the more difficult 2-back task. The FAS/PFAS group may have been activating all of the neuronal resources they had, but the resources were too deficient, not just inefficient, to achieve comparable activation or performance.

\section{FASD fMRI studies}

To our knowledge, only three fMRI-FASD studies have been published to date [14-16]. Marlisza et al. [16] examined fMRI activation patterns corresponding to $\mathrm{N}$ back spatial working memory tasks in adults and children with FASD, and in age- and sex-matched Controls. It is important to note their subjects with FASD performed too poorly on the 2-back task to include these findings, so it was dropped from all analyses. To be included in their analyses, all participants had to achieve a minimum of 50\% correct responses on the Simple task, and on at least one of the remaining $N$-back tasks (Blank or 1-back). Complete data were available for 23 children (nine FASD, 14 Controls) and 19 adults (ten FASD and nine Controls). Subjects with FASD were diagnosed with FAS, partial FAS, or ARND in accordance with the Canadian FASD diagnostic guidelines [32]. The Canadian diagnostic criteria are near identical to the FASD 4-Digit Diagnostic Code used in the present study. Children with FASD displayed greater inferior-middle frontal lobe activity, while greater superior frontal and parietal lobe activity was observed in Controls. Children in the Control group also showed an overall increase in frontal lobe activity with increasing task difficulty, while children with FASD showed decreased 
activity. Adults with FASD demonstrated less functional brain activity overall, but greater inferior middle frontal lobe activity during the simpler tasks, relative to Controls. Adults in the Control group demonstrated greater inferior frontal activity with increasing task difficulty, while this pattern was not consistently observed in adults with FASD. All four groups showed increasing activity with increases in task difficulty in the parietal and frontal regions at more superior slice levels. They concluded their results suggested impairment in spatial working memory in those with FASD that does not improve with age.

Sowel et al. [14] examined fMRI activation patterns corresponding to verbal paired associate learning in a group of 11 children with FASD (two FAS, four PFAS, five Neurobehavioral disorder/alcohol exposed diagnosed with the 2004 FASD 4-Digit Code [27]. Controls included 16 typically developing children with little or no prenatal alcohol exposure (they were excluded if they were prenatally exposed to one drink or more per week, or more than two drinks on any one occasion). Among the children with typical development, prominent activation was observed in the left medial temporal lobe, left dorsal frontal lobe, and bilateral posterior temporal cortices during learning and recall. Analyses revealed significantly less activation in left medial and posterior temporal regions and significantly more activation in right dorsal frontal cortex in the alcohol-exposed children relative to Controls, even when group differences in memory test performance were statistically controlled. The investigators concluded their results may indicate an increased reliance on frontal memory systems, when in the children with heavy prenatal alcohol exposure, perhaps compensating for dysfunctional medial temporal memory systems, when presented with a difficult verbal memory task.

Fryer et al. [15] examined fMRI activation patterns corresponding to a Go/No-Go task in a group of 13 adolescents (8-18 years old) with prenatal alcohol exposure (six FAS and seven without FAS) and nine Controls with no prenatal alcohol exposure. The alcohol-exposed group was evaluated by a dysmorphologist. No FASD diagnostic criteria were cited. The Go/No-Go task is quite different from an $\mathrm{N}$-back working memory task, as it requires response inhibition and perhaps involves a lighter working memory load. Mean total brain volume was not significantly different between the alcohol-exposed and Control groups. Interestingly, performance on the go/no-go task was also not significantly different between the alcohol-exposed group and the Control group. During portions of the task that required response inhibition, alcohol-exposed subjects showed greater blood oxygen level-dependent (BOLD) response across prefrontal cortical regions (including the left medial and right middle frontal gyri), while they showed less right caudate nucleus activation, compared to
Control subjects. The investigators concluded their results suggest that the frontal-striatal circuitry thought to mediate inhibitory control may be sensitive to alcohol teratogenesis.

Overall, the three FASD fMRI studies report significant differences in brain activation patterns were observed between FASD and Control groups during verbal learning [14], response inhibition [15], and spacial working memory [16] tasks. Significant differences in brain activation patterns were also detected between FASD and Control groups in our study of nonspatial working memory. All of these tasks require higher-order cognitive abilities that are often deficient in individuals with FASD [17-21].

In conclusion, the results of this study demonstrate it is possible (albeit challenging) to use fMRI to study brain activation in children with FASD. This study also shows that children across the full spectrum of FASD exhibit significant working memory deficits. These deficits are correlated with abnormalities in activation in brain areas that are known to be involved in working memory. Alterations in brain activation provide compelling evidence that cognitive and behavioral deficits among individuals with FASD are, to an important extent, "brain-based." An important component of a FASD diagnostic evaluation is confirmation of CNS abnormality. Our ability to detect CNS abnormalities is dependent on the sensitivity of today's measurement tools. These results demonstrate the potential research and diagnostic value of this non-invasive MR tool.

Acknowledgments This research was supported by NIAAA grant R01-AA12915-01 A1 to SJA. Support was also received from the Center on Human Development and Disability, University of Washington (National Institute of Child Health and Human Development grant P30 HD02274). Special thanks are extended to the children and their families who so kindly contributed time and effort to this study.

\section{References}

1. Smith DW. The fetal alcohol syndrome. Hosp Pract 1979;14: 121-28.

2. Astley SJ, Clarren SK. Measuring the facial phenotype of individuals with prenatal alcohol exposure: correlations with brain dysfunction. Alcohol Alcohol 2001;36:147-59.

3. Astley S, Stachowiak J, Clarren S, Clausen C. Application of the fetal alcohol syndrome facial photographic screening tool in a foster care population. J Pediatr 2002;141:712-17.

4. Aase JM, Jones KL, Clarren SK. Do we need the term "fae"? Pediatrics 1995;95:428-30.

5. Streissguth AP, Bookstein FL, Sampson PC, Barr HM. The enduring effects of prenatal alcohol exposure on child development: birth through seven years a partial least squares solution. Ann Arbor, MI: University of Michigan Press; 1993.

6. Stratton K, Howe C, Battaglia F. Fetal alcohol syndrome. Diagnosis epidemiology prevention and treatment. Washington, DC: Institute of Medicine, National Academy; 1996. 
7. Streissguth AP, Bookstein FL, Barr HM, Sampson PD, O'Malley $\mathrm{K}$, Young JK. Risk factors for adverse life outcomes in fetal alcohol syndrome and fetal alcohol effects. J Dev Behav Pediatr 2004;25:228-38.

8. Kodituwakku PW. Defining the behavioral phenotype in children with fetal alcohol spectrum disorders: a review. Neurosci Biobehav Rev 2007;31:192-201.

9. Astley SJ, Olson HC, Kerns K, Brooks A, Aylward EH, Coggins TE, Davies J, Dorn S, Gendler B, Jirikowic T, Kraegel P, Maravilla K, Richards T. Neuropsychological and behavioral outcomes from a comprehensive magnetic resonance study of children with fetal alcohol spectrum disorders. Can J Pharmacol Fetal Alcohol Res 2009; 16(1) (in press), Winter.

10. Astley SJ, Richards T, Aylward EH, Olson HC, Kerns K, Brooks A, Coggins TE, Davies J, Dorn S, Gendler B, Jirikowic T, Kraegel P, Maravilla K. Magnetic resonance spectroscopy outcomes from a comprehensive magnetic resonance study of children with fetal alcohol spectrum disorders. Magn Reson Imaging 2009 (in press).

11. Aylward EH, Richards TL, Berninger VW, Nagy WE, Field KM, Grimme AC, Richards AL, Thomson JB, Cramer SC. Instructional treatment associated with changes in brain activation in children with dyslexia. Neurology 2003;61:212-19.

12. Casey BJ, Cohen JD, Jezzard P, Turner R, Noll DC, Trainor RJ, Giedd J, Kaysen D, Hertz-Pannier L, Rapoport JL. Activation of prefrontal cortex in children during a nonspatial working memory task with functional MRI. Neuroimage 1995;2:221-29.

13. Kwon H, Menon V, Stephan E, Warsofsky IS, White CD, DyerFriedman J, Taylor AK, Glover GH, Reiss AL. Functional neuroanatomy of visuospatial working memory in fragile $\mathrm{X}$ syndrome: relationship to behavioral and molecular measures. Am J Psychiatry 2001;158:1040-51.

14. Sowell ER, Lu LH, O'Hare ED, McCourt ST, Mattson SN, O'Connor MJ, Bookheimer SY. Functional magnetic resonance imaging of verbal learning in children with heavy prenatal alcohol exposure. Neuroreport 2007;18:636-39.

15. Fryer SL, Tapert SF, Mattson SN, Paulus MP, Spadoni AD, Riley EP. Prenatal alcohol exposure affects frontal-striatal bold response during inhibitory control. Alcohol Clin Exp Res 2007;31:1.

16. Malisza KL, Allman A, Shiloff D, Jakobson L, Longstaffe S, Chudley AE. Evaluation of spatial working memory function in children and adults with fetal alcohol spectrum disorders: a functional magnetic resonance imaging study. Pediatr Res 2005;58: $1150-57$.

17. Autti-Ramo I. Twelve-year follow-up of children exposed to alcohol in utero. Dev Med Child Neurol 2000;42:406-11.

18. Connor PD, Sampson PD, Bookstein FL, Barr HM, Streissguth AP. Direct and indirect effects of prenatal alcohol damage on executive function. Dev Neuropsychol 2000;18:331-54.

19. Kodituwakku PW, Handmaker NS, Cutler SK, Weathersby EK, Handmaker SD. Specific impairments in self-regulation in children exposed to alcohol prenatally. Alcohol Clin Exp Res 1995; 19:1558-64

20. Mattson SN, Riley EP. A review of neurobehavioral deficits in children with FAS or prenatal exposure to alcohol. Alcohol Clin Exp Res 1998;22:279-94.

21. Rasmussen C. Executive functioning and working memory in fetal alcohol spectrum disorder. Alcohol Clin Exp Res 2005;29:1359-67.

22. Baddeley AD, Hitch G. Working memory in the psychology of learning and motivation. New York, NY: Academicp. 1974.

23. Smith EE, Jonides J. Storage and executive processes in the frontal lobes. Science 1999;283:1657-61.

24. Kammer T, Bellemann ME, Guckel F, Brix G, Gass A, Schlemmer $H$, Spitzer M. Functional MR imaging of the prefrontal cortex: specific activation in a working memory task. Magn Reson Imaging 1997;15:879-89.
25. Mellers JD, Bullmore E, Brammer M, Williams SC, Andrew C, Sachs N, Andrews C, Cox TS, Simmons A, Woodruff P. Neural correlates of working memory in a visual letter monitoring task: An fMRI study. Neuroreport 1995;7:109-12.

26. Owen AM, Stem CE, Look RB, Tracey I, Rosen BR, Petrides M. Functional organization of spatial and nonspatial working memory processing within the human lateral frontal cortex. Proc Natl Acad Sci U S A 1998;95:7721-26.

27. Astley SJ. Diagnostic guide for fetal alcohol spectrum disorders: the 4-digit diagnostic code, ed 3rd. Seattle, WA, University of Washington Publication Services, 2004

28. Astley SJ, Clarren SK. Diagnosing the full spectrum of fetal alcohol exposed individuals: introducing the 4-digit diagnostic code. Alcohol Alcohol 2000;35:400-10.

29. Astley SJ, Clarren SK. A case definition and photographic screening tool for the facial phenotype of fetal alcohol syndrome. J Pediatr 1996;129:33-41.

30. Astley SJ, editor. In: Fetal alcohol syndrome facial photograph analysis software. Seattle: University of Washington; 2003.

31. Bertrand J, Floyd RL, Weber MK, O'Connor M, Riley EP, Johnson KA, Cohen DE. National task force on FAS/FAE fetal alcohol syndrome: guidelines for referral and diagnosis. Atlanta, GA: Centers for Disease Control and Prevention; 2004.

32. Chudley AE, Conroy J, Cook JL, Loock C, Rosales T, LeBlanc N. Public Health Agency of Canada's National Advisory Committee on fetal alcohol spectrum disorder fetal alcohol spectrum disorder: Canadian guidelines for diagnosis. Can Med Assoc J 2005;172: S1-S21.

33. Olson HC, Feldman J, Streissguth AP, Sampson PD, Bookstein FL. Neuropsychological deficits among adolescents with fetal alcohol syndrome: clinical findings. Alcohol Clin Exp Res 1998;22:1998-2012.

34. Roebuck TM, Mattson SN, Riley EP. Behavioral and psychosocial profiles of alcohol-exposed children. Alcohol Clin Exp Res 1999;23:1070-76.

35. Scheibel RS, Pearson DA, Faria LP, Kotrla K, Aylward E, Bachevalier J, Levin HS. An fMRI study of executive functioning after severe diffuse TBI. Brain Inj 2003;17:919-30.

36. Cohen JD, Perlstein WM, Braver TS, Nystrom LE, Noll DC, Jonides J, Smith EE. Temporal dynamics of brain activation during a working memory task. Nat Rev Neurosci 1997;386: 604-08.

37. Woods RP, Cherry SR, Mazziotta JC. Rapid automated algorithm for aligning and reslicing pet images. J Comput Assist Tomogr 1992;16:620-33.

38. Woods RP, Mazziotta JC, Cherry SR. Automated image registration. Amsterdam: Elsevier; 1993.

39. Shmuel A, Augath M, Oeltermann A, Logothetis NK. Negative function MRI response correlates with decreases in neuronal activity in monkey visual area v1. Nat Neurosci 2006; 9:56977.

40. Devinsky O, Morrell MJ, Vogt BAO, Devinsky MJ, Morrell BA, Vogt A. Contributions of anterior cingulate cortex to behaviour. Brains Res Rev 1995;118:279-306.

41. Barch DM, Braver TS, Nystrom LE, Forman SD, Noll DC, Cohen JD. Dissociating working memory from task difficulty in human prefrontal cortex. Neuropsychologia 1997;35:1373-80.

42. Carter CS, Braver TS, Barch DM, Botvinick MM, Noll D, Cohen JD. Anterior cingulate cortex error detection and the online monitoring of performance. Science 1998;280:747-49.

43. Nelson CA, Monk CS, Lin J, Carver LJ, Thomas KM, Truwit CL. Functional neuroanatomy of spatial working memory in children. Dev Psychol 2000;36:109-16.

44. Carter CS, MacDonald AW, Ross LL, Stenger VA. Anterior cingulate cortex activity and impaired self-monitoring of perfor- 
mance in patients with schizophrenia: an event-related fMRI study. Am J Psychiatry 2001;158:1423-28.

45. Kiehl KA, Liddle P, Hopfinger JB. Error processing and the rostral anterior cingulate: an event-related fMRI study. Psychophysiology 2000;37:216-23.

46. Rabbitt P. Errors and error correction in choice reaction time tasks. J Exp Psychol 1966;71:264-72.

47. Klingberg T, O'Sullivan BT, Roland PE. Bilateral activation of fronto-parietal networks by incrementing demand in a working memory. Cereb Cortex 1997;7:465-71.

48. Belger A, Puce A, Krystal JH, Gore JC, Goldman-Rakic P, McCarthy G. Dissociation of mnemonic and perceptual processes during spatial and nonspatial working memory using fMRI. Hum Brain Mapp 1998;6:14-32.

49. Braver TS, Barch DM, Kelley WM, Buckner RL, Cohen NJ, Miezin FM, Snyder AZ, Ollinger JM, Akbudak E, Conturo TE, Petersen SE. Direct comparison of prefrontal cortex regions engaged by working and long-term memory tasks. Neuroimage 2001;14:48-59.

50. Carlson S, Martinkauppi S, Rama P, Salli E, Korvenoja A, Aronen HJ. Distribution of cortical activation during visuospatial n-back tasks as revealed by functional magnetic resonance imaging. Cereb Cortex 1998;8:743-52.

51. Casey BJ, Cohen JD, O’Craven K, Davidson RJ, Irwin W, Nelson CA, Noll DC, Hu X, Lowe MJ, Rosen BR, Truwitt CL, Turski PA. Reproducibility of fMRI results across four institutions using a spatial working memory task. Neuroimage 1998;8:249-61.

52. Courtney SM, Ungerleider LG, Keil K, Haxby JF. Object and spatial visual working memory activate separate neural systems in human cortex. Cereb Cortex 1996;6:39-49.
53. Goldman-Rakic PS. Topography of cognition: parallel distributed networks in primate association cortex. Annu Rev Neurosci 1988; 11:1137-56.

54. Jonides J, Schumacher EH, Smith EE, Koeppe RA, Awh E, Reuter-Lorenz PA, Marshuetz C, Willis CR. The role of parietal cortex in verbal working memory. J Neurosci 1998;18:5026-34.

55. Smith EE, Jonides J. Dissociating verbal and spatial working memory using pet. Cereb Cortex 1996;6:11-20.

56. Jha AP, McCarthy G. The influence of memory load upon delayinterval activity in a working-memory task: an event-related functional MRI study. J Cogn Neurosci 2000;12:90-105.

57. Leung HC, Gore JC, Goldman-Rakic PS. Sustained mnemonic response in the human middle frontal gyrus during on-line storage of spatial memoranda. J Cogn Neurosci 2002;14:659-71.

58. LaBar KS, Gitelman DR, Parrish TB, Mesulam M. Neuroanatomic overlap of working memory and spatial attention networks: a functional MRI comparison within subjects. Neuroimage 1999;10:695-704.

59. Thomas KM, King SW, Franzen PL, Welsh TF, Berkowitz AL, Noll DC, Birmaher V, Casey BJ. A developmental functional MRI study of spatial working memory. Neuroimage 1999;10: 327-38.

60. Reuter-Lorenz PA, Jonides JEES, Hartley A, Miller A, Marshuetz C, Koeppe RA. Age differences in the frontal lateralization of verbal and spatial working memory revealed by pet. J Cogn Neurosci 2000;12:174-87.

61. Sheridan MA, Hinshaw S, Esposito MD. Efficiency of prefrontal cortex during working memory in attention-deficit/hyperactivity disorder. J Am Acad Child Adolesc Psychiatry 2007;46:135766. 